Research Paper

\title{
Identification of novel gene expression signature in lung adenocarcinoma by using next-generation sequencing data and bioinformatics analysis
}

This article has been corrected. Correction in: Oncotarget. 2019; 10:616-616. Ya-Ling Hsu ${ }^{1, *}$, Jen-Yu Hung ${ }^{2,3, *}$, Yen-Lung Lee ${ }^{4}$, Feng-Wei Chen ${ }^{5}$, Kuo-Feng Chang ${ }^{6}$, Wei-An Chang ${ }^{3,5}$, Ying-Ming Tsai ${ }^{1,3}$, Inn-Wen Chong ${ }^{3,7}$ and Po-Lin Kuo ${ }^{5,8,9}$

${ }^{1}$ Graduate Institute of Medicine, College of Medicine, Kaohsiung Medical University, Kaohsiung, Taiwan

${ }^{2}$ School of Medicine, College of Medicine, Kaohsiung Medical University, Kaohsiung, Taiwan

${ }^{3}$ Division of Pulmonary and Critical Care Medicine, Department of Internal Medicine, Kaohsiung Medical University Hospital, Kaohsiung, Taiwan

${ }^{4}$ Division of Thoracic surgery, Department of Surgery, Kaohsiung Medical University Hospital, Kaohsiung, Taiwan

${ }^{5}$ Graduate Institute of Clinical Medicine, College of Medicine, Kaohsiung Medical University, Kaohsiung, Taiwan

${ }^{6}$ Welgene Biotech. Inc, Taipei, Taiwan

${ }^{7}$ Department of Respiratory Therapy, College of Medicine, Kaohsiung Medical University, Kaohsiung, Taiwan

${ }^{8}$ Center for Biomarkers and Biotech Drugs, Kaohsiung Medical University, Kaohsiung, Taiwan

${ }^{9}$ Institute of Medical Science and Technology, National Sun Yat-Sen University, Kaohsiung, Taiwan

*These authors have contributed equally to this work

Correspondence to: Inn-Wen Chong, email: chong@kmu.edu.tw Po-Lin Kuo, email: kuopolin@seed.net.tw

Keywords: next-generation sequencing, bioinformatics, microRNA, messenger RNA, lung adenocarcinoma

Received: July 31, $2017 \quad$ Accepted: August 28, $2017 \quad$ Published: September 18, 2017

Copyright: $\mathrm{Hsu}$ et al. This is an open-access article distributed under the terms of the Creative Commons Attribution License 3.0 (CC BY 3.0), which permits unrestricted use, distribution, and reproduction in any medium, provided the original author and source are credited.

\section{ABSTRACT}

Lung adenocarcinoma is one of the leading causes of cancer-related death worldwide. We showed transcriptomic profiles in three pairs of tumors and adjacent non-tumor lung tissues using next-generation sequencing (NGS) to screen proteincoding RNAs and microRNAs. Combined with meta-analysis from the Oncomine and Gene Expression Omnibus (GEO) databases, we identified a representative genetic expression signature in lung adenocarcinoma. There were 9 upregulated genes, and 8 downregulated genes in lung adenocarcinoma. The analysis of the effects from each gene expression on survival outcome indicated that 6 genes (AGR2, SPDEF, CDKN2A, CLDN3, SFN, and PHLDA2) play oncogenic roles, and 7 genes (PDK4, FMO2, CPED1, GNG11, IL33, BTNL9, and FABP4) act as tumor suppressors in lung adenocarcinoma. In addition, we also identified putative genetic interactions, in which there were 5 upregulated microRNAs with specific targets - hsa-miR-183-5p-BTNL9, hsa-miR-33b5p-CPED1, hsa-miR-429-CPED1, hsa-miR-182-5p-FMO2, and hsa-miR-130b-5p-IL33. These 5 microRNAs have been shown to be associated with tumorigenesis in lung cancer. Our findings suggest that these genetic interactions play important roles in the progression of lung adenocarcinoma. We propose that this molecular change of genetic expression may represent a novel signature in lung adenocarcinoma, which may be developed for diagnostic and therapeutic strategies in the future.

\section{INTRODUCTION}

Lung cancer is one of the leading causes of cancerrelated death worldwide [1]. The development and progression of lung cancer has been widely studied. Briefly, the genetic alterations or mutations occurred in a single cell, leading to cellular transformation and thus expansion into a malignant tumor [2]. Non-small cell 
lung carcinoma (NSCLC) accounts for about $80-85 \%$ of all lung cancers $[3,4]$, of which lung adenocarcinoma $(40 \%)$ is the most common subtype of NSCLC [5]. Surgery to remove cancer, with or without radiotherapy/ chemotherapy, is the standard approach for early stage lung cancer. However, the recurrence of distant metastasis $[6,7]$ or resistance to therapy $[8,9]$ often occurs, and such phenomenon is associated with critical genetic alterations involved in various biological mechanisms.

The genetic alterations related to cellular transformation are involved in various biological processes, including transcription [10], DNA repair [11], cell cycle progression [12], apoptosis [13], migration ability [14], and metabolism [15, 16]. In lung cancer, many genes have been identified as oncogenes or tumor suppressor genes, which modulate varieties of molecular functions involved in tumor development and progression $[17,18]$. Recently, small RNAs have been found to play important roles in lung cancer. MicroRNAs are a group of small non-coding RNAs containing 20-26 nucleotides, which can regulate gene expression via binding to the 3 , untranslated region ( $3^{\prime} \mathrm{UTR}$ ) of specific messenger RNAs (mRNAs). This interaction can cause mRNAs' degradation or translation inhibition [19]. The signaling pathways associated with microRNAs targeting oncogenes or tumor suppressor genes have been reported to be involved in lung cancer progression [20]. Alterations of many microRNAs in chromosome regions associated with various cancers have also been implicated [21].

Next-generation sequencing (NGS) is a powerful method to screen the entire transcriptomic profile, including messenger RNAs or small RNAs [22]. In this study, we attempted to identify the differentially expressed genes and genetic interactions of target gene-microRNA in lung adenocarcinoma combined with systematic analysis, by using bioinformatics tools, including the Oncomine [23], Gene Expression Omnibus (GEO) [24], PrognoScan [25], Kaplan-Meier plotter [26], SurvExpress [27], and miRmap databases [28]. We sought to identify novel gene expression signature and/or genetic interactions in lung adenocarcinoma via systematic bioinformatics analysis. Hopefully, the approach and findings from this study will provide new perspectives on the development of diagnostic and therapeutic strategies for lung adenocarcinoma.

\section{RESULTS}

\section{Identification of differentially expressed genes as a molecular signature in lung adenocarcinoma}

To investigate genetic expression changes in lung adenocarcinoma, we analyzed the transcriptomic profiles in 3 pairs of human specimens from lung adenocarcinoma and its adjacent normal lung tissue using next-generation sequencing (Figure 1). We focused on protein-coding RNAs and Venn diagram analysis which showed that 9 genes were upregulated (Figure 1A), whereas 8 genes were downregulated (Figure 1B) in lung adenocarcinoma tissue compared to adjacent normal lung tissue. The analysis criteria were fold change $>2$ and fragments per kilobase million $(\mathrm{FPKM})>0.3$. The hierarchical color clustering showed the expression pattern of each gene with $z$-scores $(\log 2)$ in these 3 pairs of specimens (Figure 1C). The list of 17 differentially expressed genes with FPKM is shown in Table 1. To investigate whether this genetic expression pattern could represent a molecular signature in lung adenocarcinoma, we investigated these genes in the Oncomine database, which contains different data sets of specimens from lung adenocarcinoma and normal lung tissue. We selected 7 datasets from the Oncomine database for comparison of gene expression, including Hou (normal $=65$ and lung adenocarcinoma $=45$ ), Landi $($ normal $=49$ and lung adenocarcinoma $=58)$, Selamat (normal $=58$ and lung adenocarcinoma $=58)$, Okayama (normal $=20$ and lung adenocarcinoma $=226$ ), $\mathrm{Su}$ (normal $=30$ and lung adenocarcinoma $=27)$, Wei (normal $=25$ and lung adenocarcinoma $=25$ ), and Stearman (normal $=19$ and lung adenocarcinoma $=20$ ). The heatmap analysis indicated that the genetic expression patterns of 17 genes were similar among these datasets (Figure 2), which suggests that this molecular change is consistent in lung adenocarcinoma, and may represent a novel genetic signature in lung adenocarcinoma.

We classified 17 differentially expressed genes into 6 groups by biological and molecular functions, based on literature searches (Table 2; Supplementary Table 1), including (1) transcription regulation - TOX3 and SPDEF, (2) metabolism - PDK4, FABP4, and FMO2, (3) cell cycle regulation - CDKN2A, PHLDA2, SFN, and NDRG4, (4) cellular migration - AGR2, AQP5, and CLDN3 (5) inflammation - IL33, and (6) undefined group - ZDHHC9, BTNL9, GNG11, and CPED1 (also known as C7orf58). To further elucidate the role of these genetic expression changes in cancer progression, we performed survival curve analysis using the PrognoScan, Kaplan-Meier plotter, and SurvExpress databases.

\section{Analysis of TOX3 and SPDEF in lung adenocarcinoma}

The mRNA expression of TOX3 and SPDEF between lung adenocarcinoma and normal lung tissue derived from the Oncomine database is listed in Table 3. The analysis criteria were fold change $>2, p$-value $<$ $1 \mathrm{E}-04$, and gene ranking in the top $10 \%$. The results showed that both TOX3 and SPDEF are significantly upregulated in lung adenocarcinoma, compared to normal tissue. In addition, we selected a microarray with the accession number of GSE10072 from the Gene Expression Omnibus (GEO) database for gene expression analysis. This array contains 31 pairs of clinical lung adenocarcinomas and adjacent normal tissue. The results 
showed that the mRNA expression of either TOX3 (Figure 3A) or SPDEF (Figure 3B) is upregulated in lung adenocarcinoma. To further investigate the role of TOX3 and SPDEF expression in cancer progression, we performed a survival curve analysis to evaluate the effects of gene expression in lung cancer patients with lung adenocarcinoma. The results indicated that the population with higher TOX3 expression has better survival rates (Figure 3C-3G), whereas the population with higher SPDEF expression has poorer survival outcome (Figure 3H, 3I). The prognostic values of TOX3 and SPDEF expression in lung adenocarcinoma were shown as forest plots (Figure 3J), which were derived from the PrognoScan database with a Cox $p$-value $<0.05$, and the Kaplan-Meier plotter database with a log-rank $p$-value $<0.05$.

\section{Analysis of PDK4, FMO2, and FABP4 in lung adenocarcinoma}

mRNA expression of PDK4, FMO2, and FABP4 between lung adenocarcinoma and normal lung tissue was analyzed by using the Oncomine database, and listed in Table 4. The expressions of PDK4, FMO2, and FABP4 are significantly downregulated in lung adenocarcinoma compared to normal lung tissue in several datasets, and this phenomenon was also observed in GSE10072 array (Figure 4A-4C). In cancer patients with lung

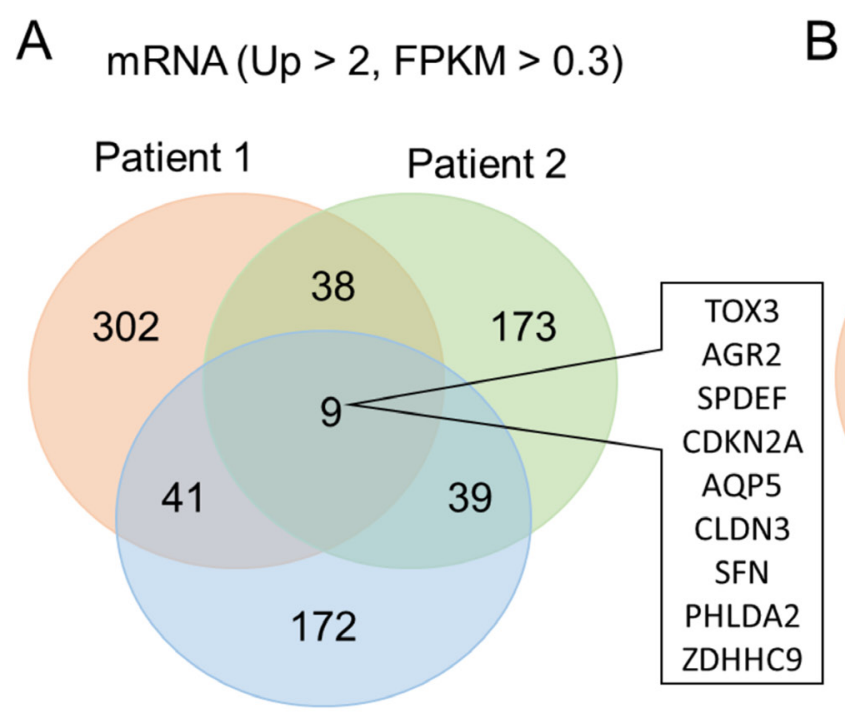

Patient 3
B $\quad$ mRNA (Down $>2$, FPKM $>0.3$ )

\section{Patient $1 \quad$ Patient 2}

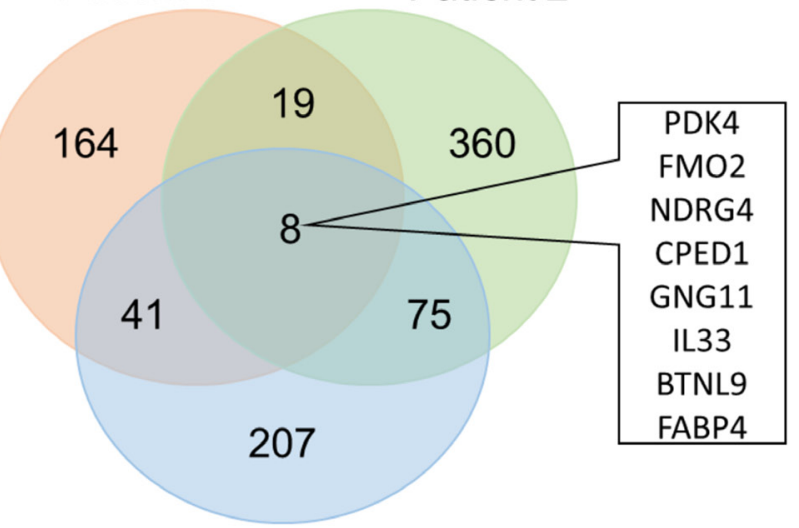

Patient 3

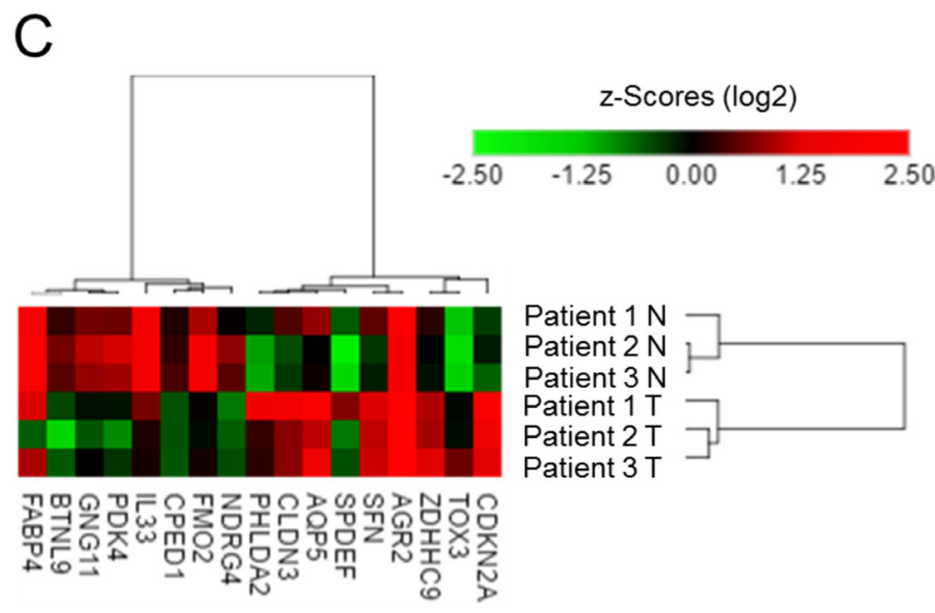

Figure 1: Identification of differentially expressed genes in lung adenocarcinoma compared to adjacent normal tissue using next-generation sequencing. Venn diagram analysis showed 9 upregulated genes (A) and 8 downregulated genes (B) in lung adenocarcinoma, compared to adjacent non-adenocarcinoma tissue from 3 pairs of clinical specimens. The criteria were fold change $>2$ (tumor/normal) and fragments per kilobase million $(\mathrm{FPKM})>0.3$. (C) The heatmap diagram showed the differentially expressed genes with z-score $(\log 2)$ values by using color clustering on GENE-E web-tool. Green represents downregulation $(\mathrm{minimum}=-2.5)$, and red represents upregulation (maximum $=2.5$ ). 
Table 1: Differentially expressed genes identified from next-generation sequencing data

\begin{tabular}{|c|c|c|c|c|c|c|c|c|}
\hline \multirow{2}{*}{ Gene } & \multirow{2}{*}{ Description } & \multicolumn{6}{|c|}{ FPKM ( fragments per kilobase million) } & \multirow{2}{*}{$\mathbf{T} / \mathbf{N}$} \\
\hline & & N1 & T1 & N2 & T2 & N3 & T3 & \\
\hline TOX3 & $\begin{array}{l}\text { TOX High Mobility Group Box } \\
\text { Family Member } 3\end{array}$ & 1.65 & 11.99 & 0.70 & 11.57 & 1.08 & 31.11 & Up \\
\hline AGR2 & $\begin{array}{l}\text { Anterior gradient 2, Protein Disulphide } \\
\text { Isomerase Family Member }\end{array}$ & 340.96 & 1530.74 & 126.15 & 864.49 & 148.26 & 955.51 & Up \\
\hline SPDEF & $\begin{array}{c}\text { SAM Pointed Domain Containing ETS } \\
\text { Transcription Factor }\end{array}$ & 5.11 & 37.10 & 0.48 & 3.91 & 0.88 & 5.90 & Up \\
\hline CDKN2A & Cyclin-Dependent Kinase Inhibitor 2A & 7.04 & 298.07 & 10.05 & 129.69 & 4.94 & 80.09 & Up \\
\hline AQP5 & Aquaporin 5 & 41.76 & 333.28 & 12.70 & 59.02 & 14.62 & 107.83 & Up \\
\hline CLDN3 & Claudin 3 & 24.83 & 104.71 & 6.02 & 38.53 & 7.31 & 39.11 & $\mathrm{Up}$ \\
\hline SFN & Stratifin & 27.16 & 75.72 & 7.48 & 59.63 & 9.59 & 65.88 & Up \\
\hline PHLDA2 & $\begin{array}{l}\text { Pleckstrin Homology-Like Domain, } \\
\text { Family A, Member } 2\end{array}$ & 9.07 & 96.14 & 2.60 & 19.93 & 2.36 & 18.58 & Up \\
\hline ZDHHC9 & Zinc finger, DHHC-type containing 9 & 17.89 & 53.14 & 12.38 & 49.49 & 11.08 & 78.66 & Up \\
\hline PDK4 & Pyruvate Dehydrogenase Kinase 4 & 30.91 & 10.82 & 72.24 & 3.18 & 47.76 & 7.63 & Down \\
\hline FMO2 & Flavin Containing Monooxygenase 2 & 50.62 & 13.47 & 138.82 & 11.57 & 185.08 & 15.11 & Down \\
\hline NDRG4 & NDRG Family Member 4 & 13.43 & 3.88 & 40.80 & 5.08 & 26.46 & 6.07 & Down \\
\hline CPED1 & $\begin{array}{c}\text { Cadherin-like and PC-esterase Domain } \\
\text { Containing } 1\end{array}$ & 16.73 & 5.70 & 19.42 & 5.68 & 23.24 & 5.39 & Down \\
\hline GNG11 & G Protein Subunit Gamma 11 & 32.96 & 11.15 & 57.85 & 5.37 & 42.70 & 12.85 & Down \\
\hline IL33 & Interleukin 33 & 117.77 & 33.34 & 133.98 & 16.49 & 153.31 & 15.49 & Down \\
\hline BTNL9 & Butyrophilin-like 9 & 19.57 & 6.43 & 32.15 & 0.92 & 26.15 & 5.25 & Down \\
\hline FABP4 & Fatty Acid Binding Protein 4 & 252.56 & 74.90 & 486.96 & 5.08 & 459.21 & 49.26 & Down \\
\hline
\end{tabular}

adenocarcinoma, the survival curve analysis indicated that the population with higher expression of PDK4 (Figure 4D-4F), FMO2 (Figure 4G-4I), or FABP4 (Figure 4J) is correlated with better survival rates. The prognostic values of PDK4, FMO2, and FABP4 are shown in Figure 4K.

\section{Analysis of CDKN2A, NDRG4, SFN, and PHLDA2 in lung adenocarcinoma}

We observed that the expression of CDKN2A, PHLDA2, and SFN are upregulated and the expression of NDRG4 is downregulated in lung adenocarcinoma when compared to normal lung tissue, which was also confirmed by the Oncomine database, listed in Table 5. In the GSE10072 array, expression levels of CDKN2A, PHLDA2, and SFN are significantly upregulated in lung adenocarcinoma compared to normal lung tissue in several datasets (Figure 5A-5C), and NDRG4 is downregulated (Figure 5D). The survival curve analysis showed that lung adenocarcinoma patients with high levels of CDKN2A expression are associated with poorer survival rates (Figure 5E). The expression level of NDRG4, however, has no significant effects on survival outcomes for patients with lung adenocarcinoma (Figure 5F). Higher expressions of PHLDA2 (Figure 5G, 5H), or SFN (Figure 5I-5K) are also associated with poorer survival. The forest plots showed the prognostic values of CDKN2A, PHLDA2, SFN, and NDRG4 (Figure 5L).

\section{Analysis of AGR2, CLDN3, and AQP5 in lung adenocarcinoma}

Analysis of mRNA expression from the Oncomine database revealed that AGR2, AQP5, and CLDN3 are upregulated in lung adenocarcinoma, compared to normal lung tissue, and these results are listed in Table 6. In the GSE10072 array, we also observed that expression levels of AGR2 and CLDN3 are significantly upregulated in lung adenocarcinoma when compared to normal lung tissue (Figure 6A, 6B). However, the expression of AQP5 showed no significant change in the GSET10072 array (Figure 6C). The survival curve analysis showed that high expression of CLDN3 is correlated with poorer rates of survival in lung adenocarcinoma patients (Figure 6D). However, the population with a higher expression of AQP5 has better survival outcome (Figure 6E-6G). Higher expression of AGR2 is also associated with poorer survival rates (Figure 6H). The prognostic values of AGR2, CLDN3, and AQP5 were shown as forest plots (Figure 6I). 
Table 2: Functional classification of differentially expressed genes

\begin{tabular}{|c|c|c|c|}
\hline Functions & Genes & Fold change (Cancer/Normal) & References $^{\#}$ \\
\hline \multirow{3}{*}{ Transcriptional regulation } & TOX3 & UP & 1 \\
\hline & SPDEF & UP & 2 \\
\hline & PDK4 & DOWN & 3 \\
\hline \multirow[t]{3}{*}{ Metabolism } & FABP4 & DOWN & 4 \\
\hline & FMO2 & DOWN & 5,6 \\
\hline & CDKN2A & UP & 7 \\
\hline \multirow{4}{*}{ Cell cycle regulation } & PHLDA2 & UP & 8,9 \\
\hline & NDRG4 & DOWN & 10 \\
\hline & SFN & UP & 11 \\
\hline & AGR2 & UP & 12 \\
\hline \multirow[t]{2}{*}{ Cellular migration } & AQP5 & UP & 13 \\
\hline & CLDN3 & UP & 14 \\
\hline \multirow[t]{2}{*}{ Inflammation } & IL33 & DOWN & 15 \\
\hline & ZDHHC9 & UP & 16 \\
\hline \multirow{3}{*}{ Others } & BTNL9 & DOWN & 17 \\
\hline & GNG11 & DOWN & 18 \\
\hline & CPED1 & DOWN & 19 \\
\hline
\end{tabular}

\# References were list in Supplementray Table 1.

Table 3: Analysis of TOX3 and SPDEF mRNA expression in lung adenocarcinoma compared to normal tissue from Oncomine database

\begin{tabular}{|c|c|c|c|c|c|c|}
\hline Gene & $\begin{array}{c}\text { Fold change } \\
\text { (Cancer/Normal) }\end{array}$ & $P$-value & $\begin{array}{c}\text { Gene Ranking } \\
\text { (Top\%) }\end{array}$ & $\begin{array}{c}\text { Samples } \\
\text { (Normal : Tumor) }\end{array}$ & Dataset & Probe \\
\hline \multirow{7}{*}{ TOX3 } & 8.685 & $1.18 \mathrm{E}-22$ & 1 & $20: 226$ & Okayama & 215108_x_at \\
\hline & 19.973 & $1.86 \mathrm{E}-24$ & 1 & $25: 25$ & Wei & 214774_x_at \\
\hline & 4.968 & $2.80 \mathrm{E}-18$ & 2 & $49: 58$ & Landi & 216623_x_at \\
\hline & 8.497 & $1.79 \mathrm{E}-9$ & 1 & $30: 27$ & $\mathrm{Su}$ & 216623_x_at \\
\hline & 3.15 & $3.09 \mathrm{E}-4$ & 2 & $17: 132$ & Bhattacharjee & 37426_at \\
\hline & 12.617 & $2.17 \mathrm{E}-7$ & 3 & $19: 20$ & Stearman & 37426_at \\
\hline & 3.764 & 4.72E-7 & 10 & $65: 45$ & Hou & 216623_x_at \\
\hline \multirow{5}{*}{ SPDEF } & 3.719 & $1.54 \mathrm{E}-11$ & 5 & $20: 226$ & Okayama & 213441_x_at \\
\hline & 3.451 & $2.64 \mathrm{E}-12$ & 1 & $25: 25$ & Wei & 220192_x_at \\
\hline & 5.44 & $2.86 \mathrm{E}-9$ & 1 & $30: 27$ & $\mathrm{Su}$ & 220192_x_at \\
\hline & 2.12 & $1.94 \mathrm{E}-7$ & 9 & $65: 45$ & Hou & 220192_x_at \\
\hline & 3.844 & $9.6 \mathrm{E}-17$ & 2 & $58: 58$ & Selamat & ILMN_2161330 \\
\hline
\end{tabular}


Analysis of IL33 in lung adenocarcinoma

The mRNA expression of IL33 is significantly downregulated in lung adenocarcinoma compared to normal tissue (Table 7). We also found that IL33 expression is decreased in lung adenocarcinoma identified from the GSE10072 array (Figure 7A). The survival curve analysis performed using the SurvExpress database showed that the high risk population with lower expression of IL33 has poorer survival outcomes for lung adenocarcinoma patients (Figure 7B, 7C). This phenomenon was also observed in the PrognoScan
(Figure 7D-7F) and Kaplan-Meier plotter databases (Figure 7G). The prognostic values of IL33 in lung adenocarcinoma was illustrated as a forest plot (Figure $7 \mathrm{H}$ ).

\section{Analysis of ZDHHC9, BTNL9, GNG11, and CPED1 in lung adenocarcinoma}

The mRNA expression of BTNL9, GNG11, or CPED1 is downregulated in lung adenocarcinoma when compared to normal tissue, and ZDHHC9 is upregulated (Table 8). In the GSE10072 array, GNG11 (Figure 8A)

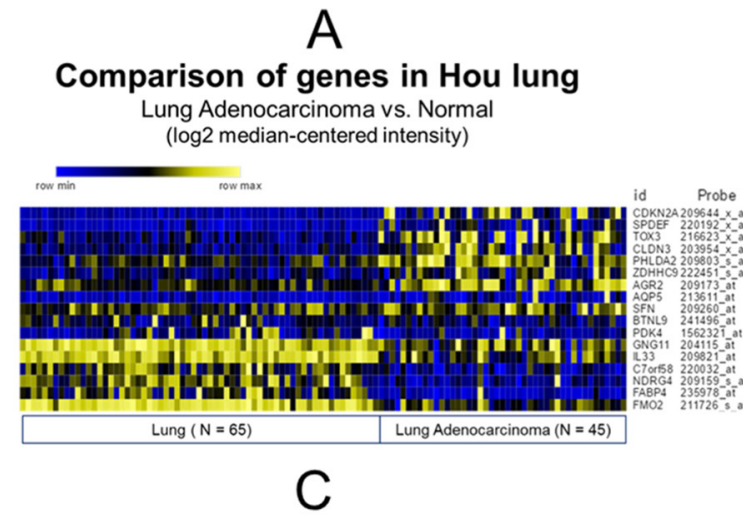

\section{Comparison of genes in Selamat lung Lung Adenocarcinoma vs. Normal (log2 median-centered intensity)}
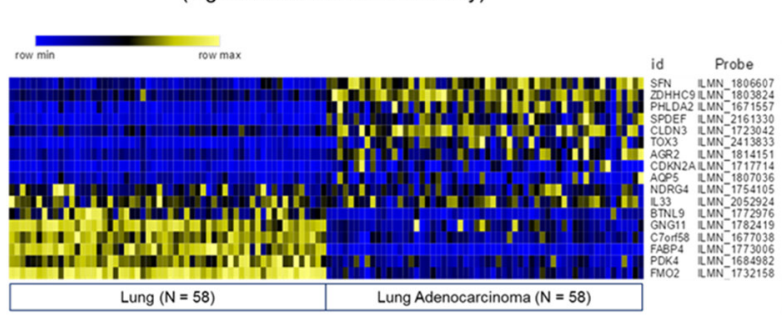

\section{Comparison of genes in Landi lung Lung Adenocarcinoma vs. Normal}

(log2 median-centered intensity)
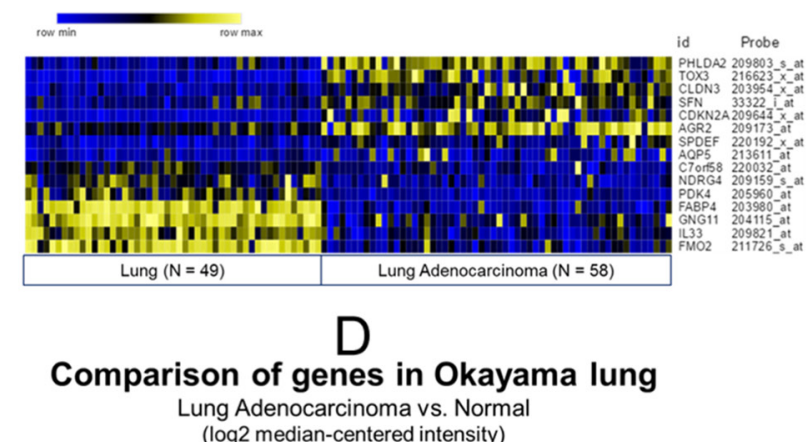
(log2 median-centered intensity)
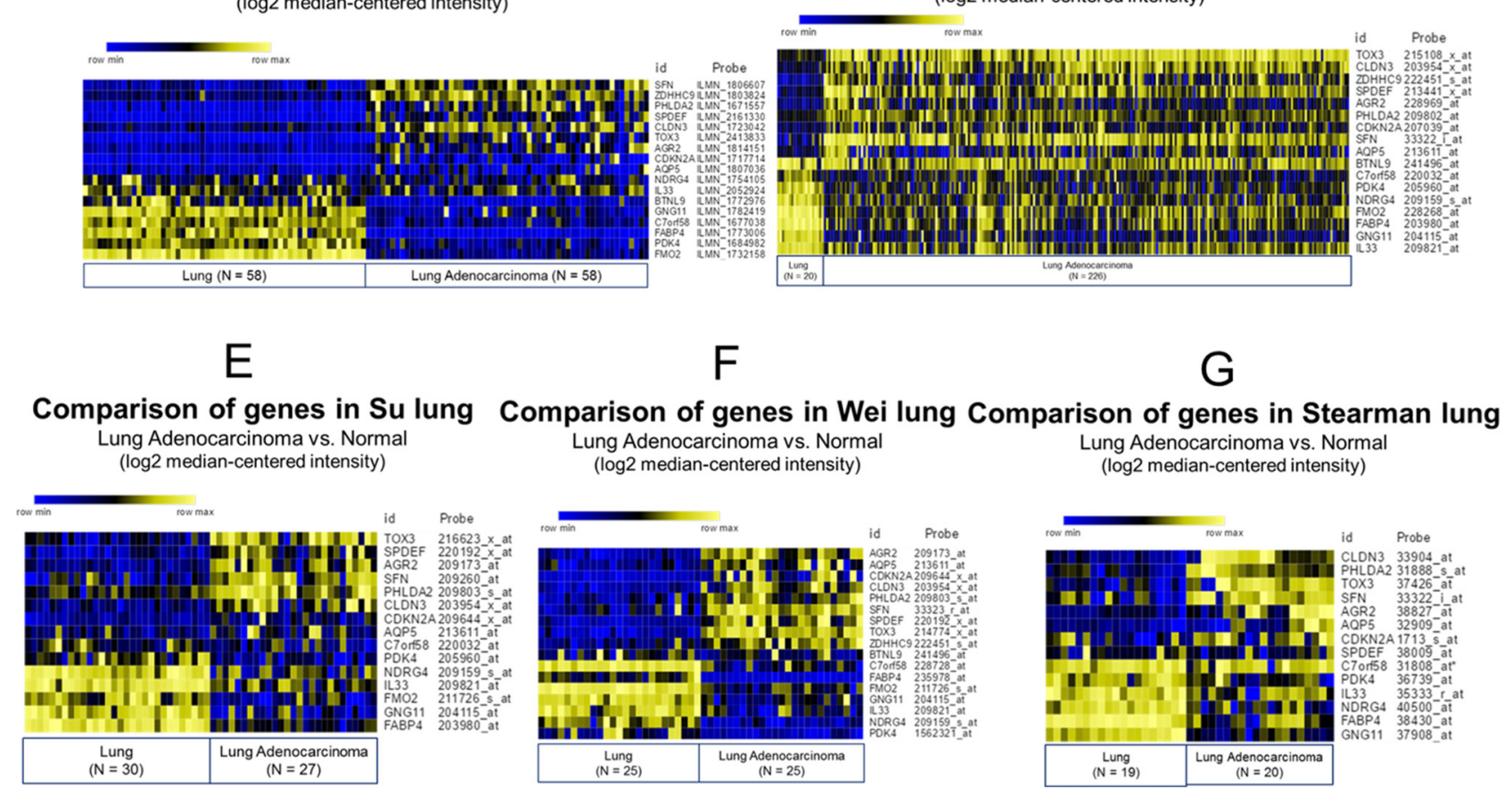

Figure 2: Comparison of differentially expressed genes in clinical lung adenocarcinoma and normal lung tissue by Oncomine database analysis. Seven microarray datasets from the Oncomine database were used to analyze gene expression patterns (lung adenocarcinoma vs. normal), including (A) Hou, (B) Landi, (C) Selamat, (D) Okayama, (E) Su, (F) Wei, and (G) Stearman. Seventeen differentially expressed genes ( 9 up and 8 down) identified from 3 pairs of clinical lung adenocarcinoma were selected. Raw data were extracted and re-plotted by GENE-E web-tool, and the relative color scheme used for clustering analysis. Yellow represents high expression $($ maximum $=1)$ and blue represents low expression $(\operatorname{minimum}=0)$. The gene symbols and corresponding specific probes are displayed on the right side of each diagram. 
A TOX3 Expression

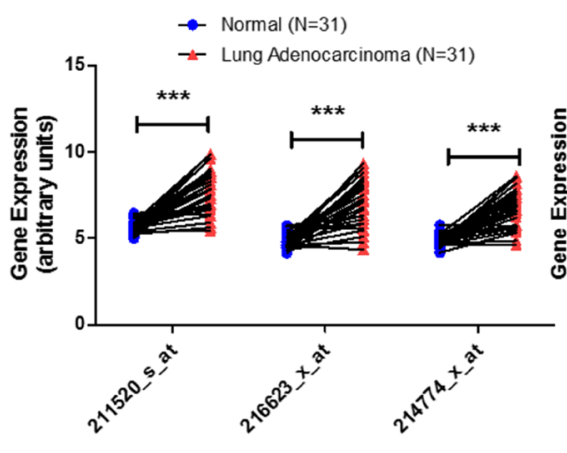

D

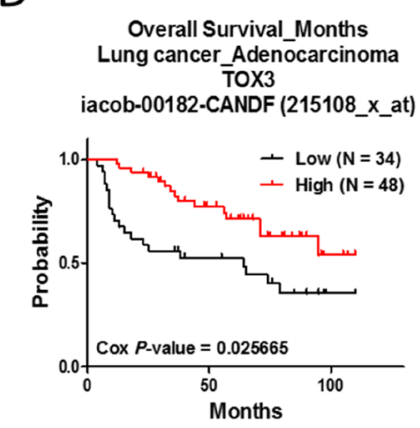

G

Overall Survival_Months Lung cancer_Adenocarcinoma TOX3 KM Plotter (214774_x_at)

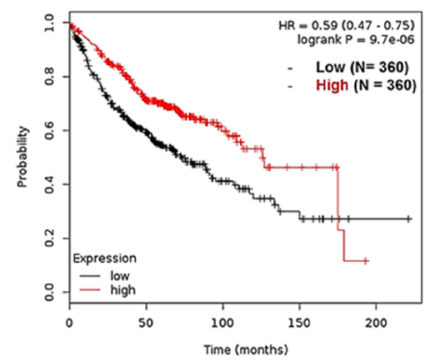

B SPDEF Expression Adjacent Normal vs. Lung Adenocarcinoma $\rightarrow \operatorname{Nomal}(\mathrm{N}=31)$ - Lung Adenocarcinoma ( $N=31)$

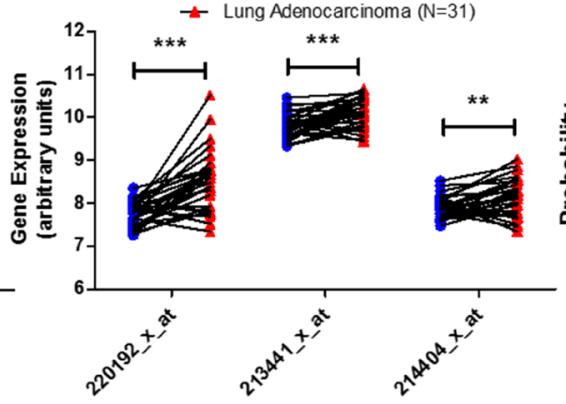

E

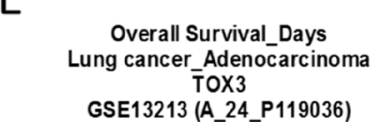

F
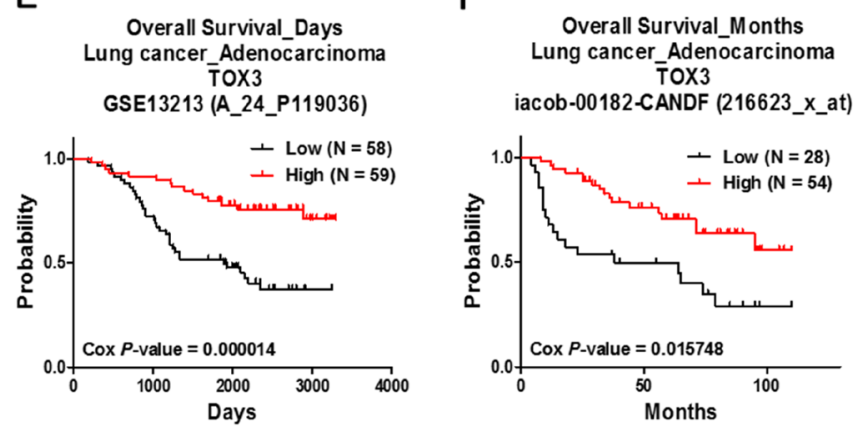

$\mathrm{H}$

Overall Survival_Days Lung cancer_Adenocarcinoma SPDEF iacob-00182-UM (214403_x_at)

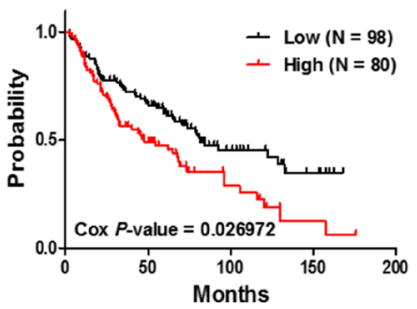

C Overall Survival_Months Lung cancer_Adenócarcinoma TOX 3 iacob-00182-HLM (215108_x_at)

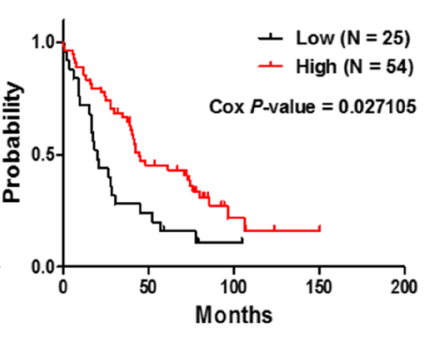

J

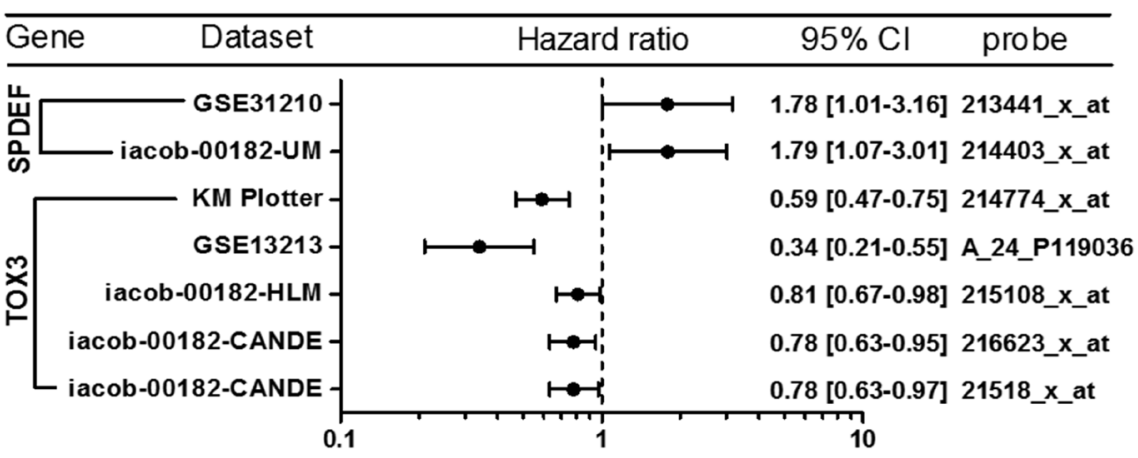

Figure 3: Analysis of TOX3 and SPDEF in clinical lung adenocarcinoma patients using bioinformatics databases. The gene expression of TOX3 (A) and SPDEF (B), comparing 31 pairs of clinical lung adenocarcinoma (red) and adjacent normal tissue (blue), was performed on GSE10072 microarray from the GEO database. (3 probes for TOX3 and SPDEF respectively in GSE10072) The $p$-value of gene expression was calculated by $t$-test with Wilcoxon matched-pairs signed rank test. ${ }^{* * *}$ represents $p<0.001$, ${ }^{* *}$ represents $p<0.01$. The survival curves comparing 2 populations with high (red) and low (black) gene expression in lung adenocarcinoma patients were performed on the PrognoScan database - TOX3 (C-F) and SPDEF (H, I), and the Kaplan-Meier plotter database - TOX3 (G). The analysis criteria of the PrognoScan and Kaplan-Meier plotter databases were Cox $p$-value $<0.05$ and log-rank $p$-value $<0.05$ respectively. The raw data of GEO and PrognoScan databases were extracted and re-plotted by GraphPad Prism 5 software. (J) The forest plots showed hazard ratios (95\% CI, confidence interval) identified from PrognoScan and Kaplan-Meier plotter databases. 
Table 4: Analysis of PDK4, FMO2 and FABP4 mRNA expression in lung adenocarcinoma compared to normal tissue from Oncomine database

\begin{tabular}{|c|c|c|c|c|c|c|}
\hline Gene & $\begin{array}{c}\text { Fold change } \\
\text { (Cancer/Normal) }\end{array}$ & $P$-value & $\begin{array}{l}\text { Gene Ranking } \\
\text { (Top\%) }\end{array}$ & $\begin{array}{c}\text { Samples } \\
\text { (Normal : Tumor) }\end{array}$ & Dataset & Probe \\
\hline \multirow{9}{*}{ PDK4 } & -5.162 & $1.27 \mathrm{E}-24$ & 1 & $20: 226$ & Okayama & 225207_at \\
\hline & -9.834 & $2.27 \mathrm{E}-13$ & 2 & $25: 25$ & Wei & 225207 at \\
\hline & -2.415 & $1.92 \mathrm{E}-16$ & 4 & $49: 58$ & Landi & 205960_at \\
\hline & -4.074 & $2.98 \mathrm{E}-7$ & 5 & $30: 27$ & $\mathrm{Su}$ & 205960_at \\
\hline & -4.33 & $1.56 \mathrm{E}-4$ & 8 & $17: 132$ & Bhattacharjee & 36739_at \\
\hline & -2.618 & $1.77 \mathrm{E}-4$ & 9 & $19: 20$ & Stearman & 36739_at \\
\hline & -4.593 & $6.29 \mathrm{E}-27$ & 2 & $58: 58$ & Selamat & ILMN_1684982 \\
\hline & -3.095 & $9.03 \mathrm{E}-7$ & 7 & $10: 86$ & Beer & U54617_at \\
\hline & -10.368 & $2.77 \mathrm{E}-6$ & 2 & $5: 40$ & Garber & IMAGE:78946 \\
\hline \multirow{8}{*}{ FMO2 } & -3.77 & $4.98 \mathrm{E}-18$ & 1 & $20: 226$ & Okayama & 211726_s_at \\
\hline & -7.811 & $4.49 \mathrm{E}-15$ & 2 & $25: 25$ & Wei & 228268_at \\
\hline & -5.528 & $6.60 \mathrm{E}-28$ & 1 & $49: 58$ & Landi & 211726_s_at \\
\hline & -4.329 & $2.47 \mathrm{E}-10$ & 2 & $30: 27$ & $\mathrm{Su}$ & 211726_s_at \\
\hline & -8.705 & $1.62 \mathrm{E}-53$ & 1 & $58: 58$ & Selamat & ILMN_1732158 \\
\hline & -9.102 & $1.02 \mathrm{E}-24$ & 1 & $65: 65$ & Hou & 228268_at \\
\hline & -7.56 & $7.38 \mathrm{E}-6$ & 2 & $5: 39$ & Garber & IMAGE:80507 \\
\hline & -11.062 & $9.47 \mathrm{E}-19$ & 1 & $10: 86$ & Beer & Y09267_at \\
\hline \multirow{9}{*}{ FABP4 } & -14.421 & $9.74 \mathrm{E}-28$ & 1 & $20: 226$ & Okayama & 203980_at \\
\hline & -20.112 & $1.42 \mathrm{E}-17$ & 1 & $25: 25$ & Wei & 203980_at \\
\hline & -19.625 & $1.89 \mathrm{E}-17$ & 1 & $30: 27$ & $\mathrm{Su}$ & 203980_at \\
\hline & -14.293 & $1.90 \mathrm{E}-37$ & 1 & $49: 58$ & Landi & 203980_at \\
\hline & -68.043 & $3.67 \mathrm{E}-13$ & 1 & $17: 132$ & Bhattacharjee & 38430_at \\
\hline & -13.918 & $2.07 \mathrm{E}-7$ & 4 & $19: 20$ & Stearman & 38430_at \\
\hline & -26.532 & $1.26 \mathrm{E}-12$ & 2 & $10: 86$ & Beer & J02874_at \\
\hline & -9.214 & $1.34 \mathrm{E}-5$ & 3 & $5: 40$ & Garber & IMAGE:2308848 \\
\hline & -12.842 & $5.80 \mathrm{E}-44$ & 1 & $58: 58$ & Selamat & ILMN_1773006 \\
\hline
\end{tabular}

and CPED1 (Figure 8B) expression is downregulated in lung adenocarcinoma. There is no specific probe for ZDHHC9 and BTNL9 in the GSE10072 array. Survival curve analysis revealed that lung adenocarcinoma patients with high expression of ZDHHC9 (Figure 8C), BTNL9 (Figure 8D-8F), GNG11 (Figure 8G, 8H) or CPED1 (Figure $8 \mathrm{I}-8 \mathrm{~K}$ ) are correlated with better survival outcomes. The forest plot showed the prognostic values of ZDHHC9, BTNL9, GNG11, and CPED1 (Figure 8L).

\section{Identification of genetic regulation in lung adenocarcinoma using next-generation sequencing}

We simultaneously performed small RNA-seq in these 3 pairs of specimens using next-generation sequencing (Figure 9). We focused on microRNAs and found 22 upregulated microRNAs in lung adenocarcinoma using Venn diagram analysis (Figure 9A), which is listed in Table 9. The analysis criteria were fold change $>2$ and reads per million $(\mathrm{RPM})>1$. No microRNA with downregulated changes were found in our analysis (Figure 9B). Heatmap color clustering showed the expression patterns of each upregulated microRNA from these 3 pairs of specimens (Figure 9C). To further elucidate the genetic interactions in lung adenocarcinoma, we performed miRmap database for target prediction. Among 22 upregulated microRNAs, there were 13 putative targets, shown in the "Targets" Venn diagram (Figure 9D). The prediction threshold was miRmap score $>90.0$. The Venn diagram analysis between 13 targets of microRNAs and 8 downregulated genes, shown in Figure 1B, indicates that there were 10 genetic interactions of microRNA-mRNA in lung adenocarcinoma (Figure 9D), which is listed in Table 10. Only 6 genes were involved in these 10 genetic interactions, due to the 3 genes have been attributed to different microRNAs.

\section{DISCUSSION}

Lung cancer, one of the leading causes of cancerrelated death worldwide [29], still has much that requires 
A PDK4 Expression $\quad$ B FMO2 Expression Adjacent Normal vs. Lung Adenocarcinoma $\rightarrow$ Normal $(\mathrm{N}=31)$

\- Lung Adenocarcinoma ( $\mathrm{N}=31)$

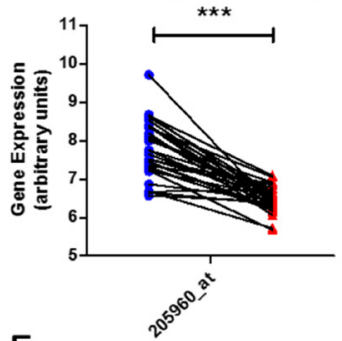

E

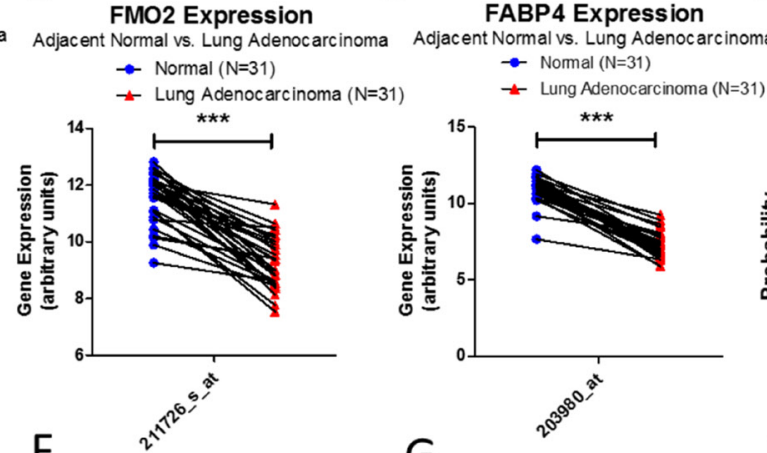

D
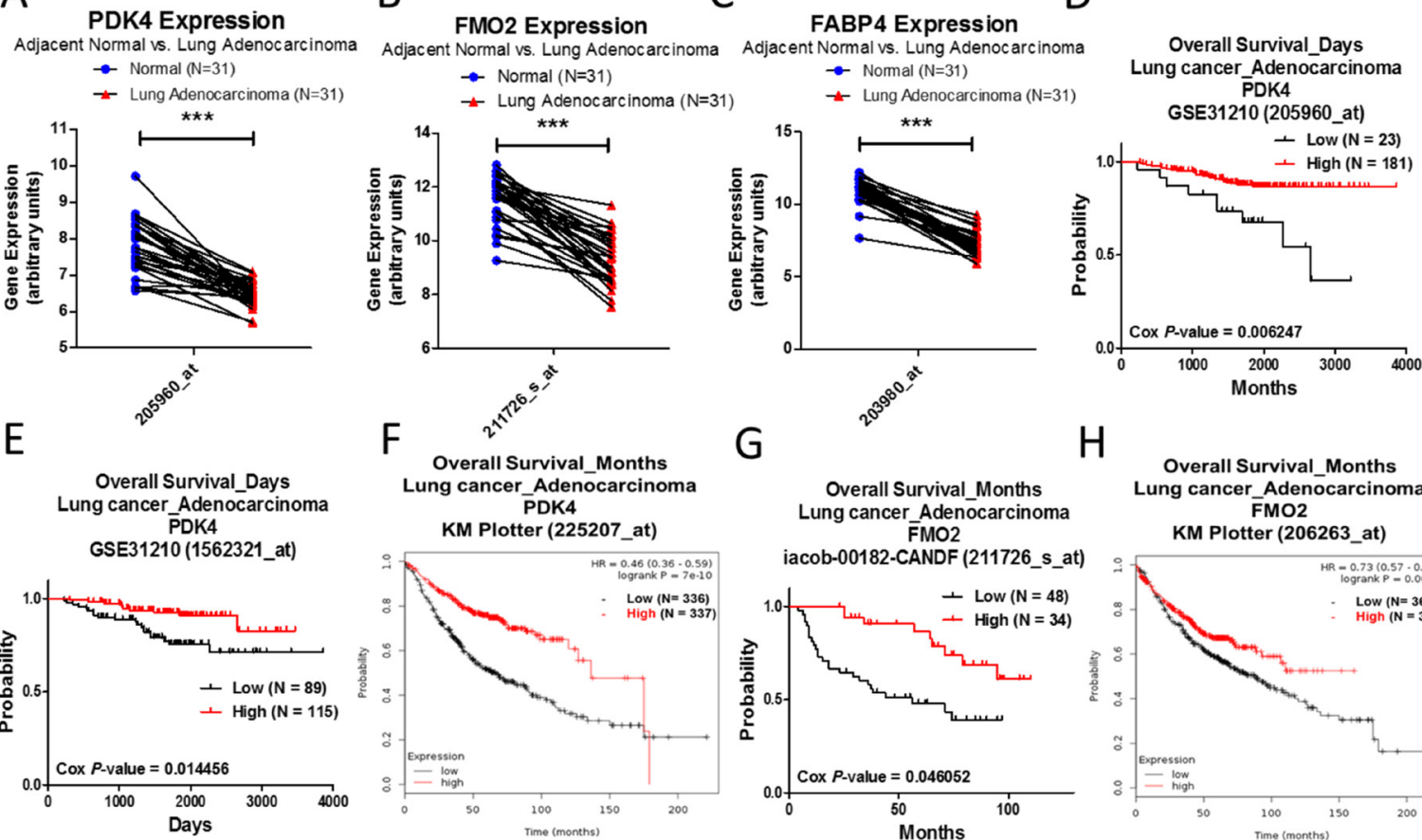

F $2 \imath_{\text {Overall Survival_Months }}^{2}$ Lung cancer_Adenocarcinoma KM Plotter (225207_at)

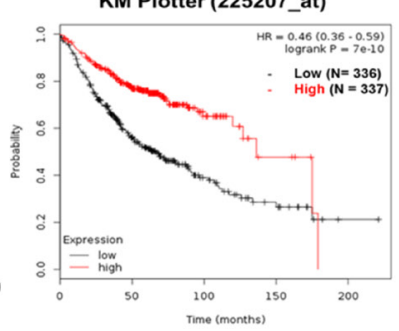

G

$\mathrm{H}$

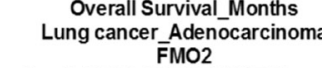
Overall Survival_Months Lung cancer_Adenocarcinoma Lung cancer FMO
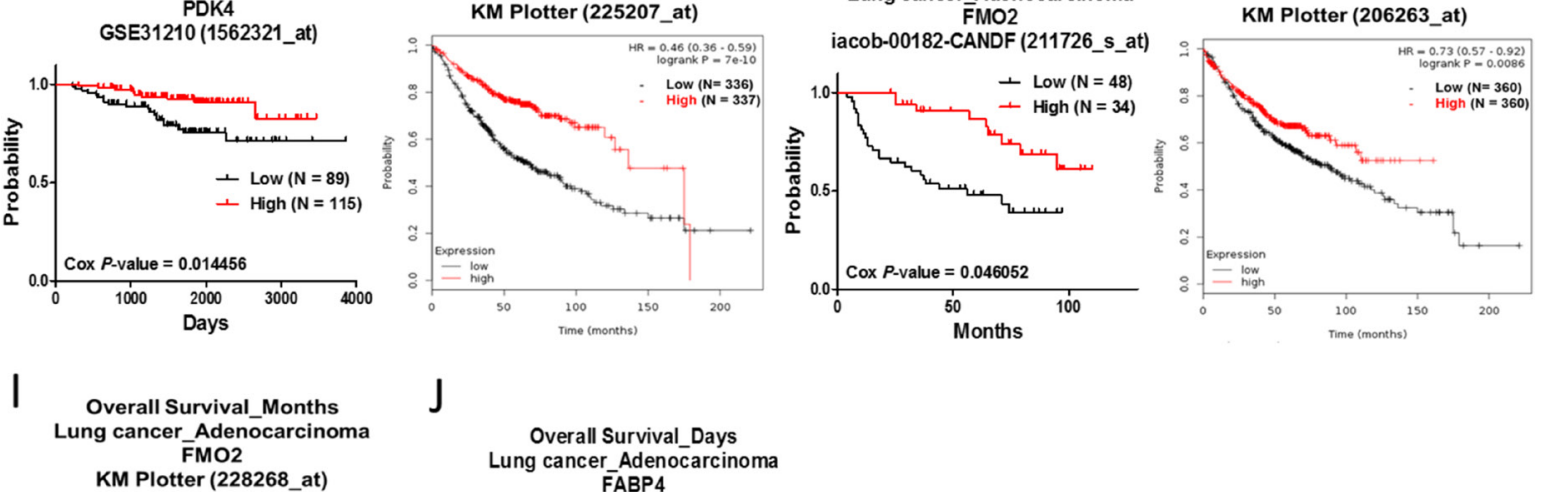

J
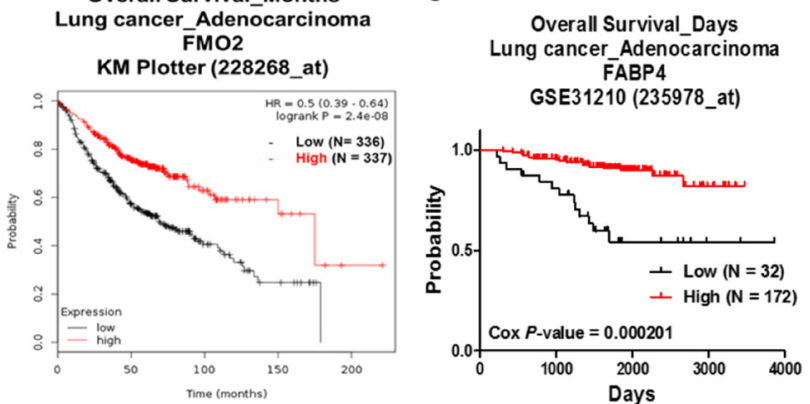

K

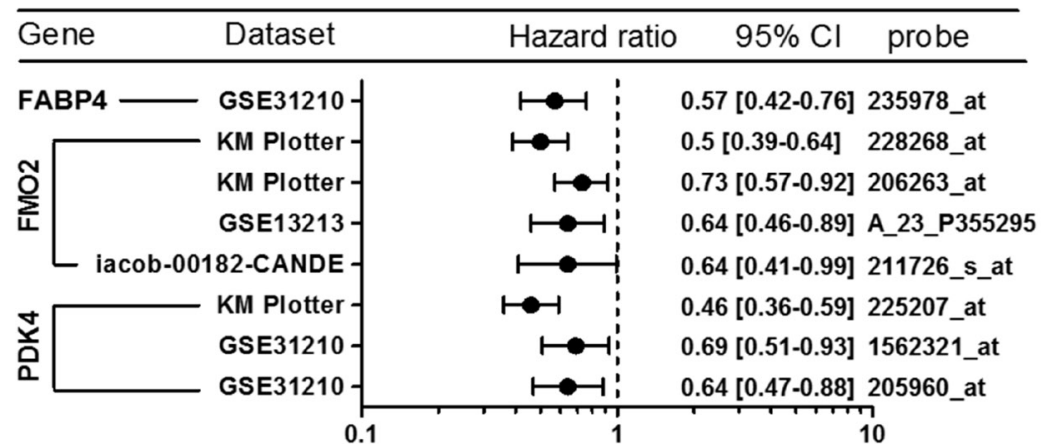

Figure 4: Analysis of PDK4, FMO2 and FABP4 in clinical lung adenocarcinoma patients using bioinformatics databases. The gene expression of PDK4 (A), FMO2 (B), and FABP4 (C), comparing 31 pairs of clinical lung adenocarcinoma (red) and adjacent normal tissue (blue), was performed on GSE10072 microarray from the GEO database. The $p$-value of gene expression was calculated by $t$-test with Wilcoxon matched-pairs signed rank test. ${ }^{* *}$ represents $p<0.001$. The survival curves comparing 2 populations with high (red) and low (black) gene expression in lung adenocarcinoma patients were performed on the PrognoScan database - PDK4 $(\mathbf{D}, \mathbf{E})$, FMO2 (G), and FABP4 (J), and the Kaplan-Meier plotter database - PDK4 (F) and FMO2 $(\mathbf{H}, \mathbf{I})$. The analysis criteria of the PrognoScan and Kaplan-Meier plotter databases were Cox $p$-value $<0.05$ and $\log$-rank $p$-value $<0.05$ respectively. Raw data of the GEO and the PrognoScan databases were extracted and re-plotted by GraphPad Prism 5 software. (K) The forest plots showed hazard ratios $(95 \%$ CI, confidence interval) identified from the PrognoScan and Kaplan-Meier plotter databases. 
Table 5: Analysis of CDKN2A, PHLDA2, SFN, and NDRG4 mRNA expression in lung adenocarcinoma compared to normal tissue from Oncomine database

\begin{tabular}{ccccccc}
\hline Gene & $\begin{array}{c}\text { Fold change } \\
\text { (Cancer/Normal) }\end{array}$ & $\boldsymbol{P}$-value & $\begin{array}{c}\text { Gene Ranking } \\
\text { (Top\%) }\end{array}$ & $\begin{array}{c}\text { Samples } \\
\text { (Normal : Tumor) }\end{array}$ & Dataset & Probe \\
\hline \multirow{6}{*}{ CDKN2A } & 2.793 & $1.08 \mathrm{E}-8$ & 1 & $20: 226$ & Okayama & 225207_at \\
& 3.203 & $2.43 \mathrm{E}-6$ & 2 & $25: 25$ & Wei & 225207_at \\
& 2.030 & $7.82 \mathrm{E}-11$ & 4 & $49: 58$ & Landi & 205960_at \\
& 3.161 & $4.32 \mathrm{E}-9$ & 5 & $65: 45$ & Hou & 205960_at \\
& 2.206 & 0.01 & 8 & $19: 20$ & Stearman & 36739_at \\
& 3.506 & $7.68 \mathrm{E}-4$ & 9 & $10: 86$ & Beer & 36739_at \\
PHLDA2 & 4.207 & $4.25 \mathrm{E}-9$ & 1 & $25: 25$ & Wei & 211726_s_at \\
& 5.73 & $1.80 \mathrm{E}-4$ & 2 & $17: 132$ & Bhattacharjee & 228268_at \\
& 4.027 & $1.99 \mathrm{E}-19$ & 1 & $49: 58$ & Landi & 211726_s_at \\
& 3.634 & $1.09 \mathrm{E}-7$ & 2 & $30: 27$ & Su & 211726_s_at \\
& 2.387 & $1.42 \mathrm{E}-17$ & 1 & $58: 58$ & Selamat & ILMN_1732158 \\
& 2.212 & $1.35 \mathrm{E}-5$ & 1 & $65: 45$ & Hou & 228268_at \\
& 4.015 & $9.11 \mathrm{E}-8$ & 2 & $19: 20$ & Stearman & IMAGE:80507 \\
& 2.799 & $2.05 \mathrm{E}-11$ & 1 & $10: 86$ & Beer & Y09267_at \\
& 4.721 & $1.98 \mathrm{E}-11$ & 2 & $25: 25$ & Wei & 33323_r_at \\
& 2.049 & $1.60 \mathrm{E}-12$ & 5 & $49: 58$ & Landi & 33322_i_at \\
& 6.459 & $3.04 \mathrm{E}-8$ & 2 & $30: 27$ & Su & 209260_at \\
& 2.410 & $4.06 \mathrm{E}-6$ & 5 & $19: 20$ & Stearman & 33322_i_at \\
& 4.487 & $1.67 \mathrm{E}-24$ & 1 & $58: 58$ & Selamat & ILMN_1806607 \\
& 2.302 & $2.74 \mathrm{E}-5$ & 6 & $10: 86$ & Beer & X57348_s_at \\
& -3.519 & $1.78 \mathrm{E}-12$ & 1 & $20: 226$ & Okayama & 203980_at \\
& -5.009 & $1.03 \mathrm{E}-13$ & 1 & $25: 25$ & Wei & 203980_at \\
& -3.923 & $5.21 \mathrm{E}-9$ & 1 & $30: 27$ & Su & 203980_at \\
& -4.402 & $2.32 \mathrm{E}-7$ & 4 & $19: 20$ & Stearman & 38430_at \\
& -2.448 & $1.60 \mathrm{E}-14$ & 2 & $65: 45$ & Hou & J02874_at \\
& -3.152 & $4.63 \mathrm{E}-4$ & 3 & $5: 40$ & Garber & IMAGE:2308848 \\
& -3.007 & $1.04 \mathrm{E}-18$ & 1 & $58: 58$ & Selamat & ILMN_1773006 \\
\hline
\end{tabular}

further study. In our project, we hoped to identify novel gene expression signature or genetic interactions of gene-microRNA in lung adenocarcinoma by using next-generation sequencing combined with systematic bioinformatics analysis.

We found 17 differentially expressed genes in lung adenocarcinoma compared to its adjacent normal lung tissue, which were classified into 6 functional groups based on a search of the literature. These results indicated that tumor progression is involved in alterations of various biological functions. We then summarized the potential oncogenic and tumor suppressor roles of these genes in lung adenocarcinoma (Supplementary Table 2).

TOX3 contains an HMG-box (high mobility group box) domain. The function of TOX3 remains unclear, but it may be involved in various DNA-dependent processes [30-32]. TOX3 polymorphisms and epigenetic regulation have been demonstrated in breast cancer [33] and lung cancer [34] respectively. In our study, TOX3 was significantly upregulated in lung adenocarcinoma, and higher expression of TOX3 is correlated with better survival outcome. We speculated that as more factors may be involved in TOX3-related mechanisms of tumor progression, more studies are needed to clarify the relationship between TOX3 expression and tumor progression.

SPDEF containing ETS domain has been reported to be overexpressed in many cancers [35-37]. Our study suggests that SPDEF may play an oncogenic role in lung adenocarcinoma, although some reports have shown that SPDEF can suppress cancer metastasis [38]. However, contrary effects of SPDEF on tumorigenesis require further research.

PDK4 is a mitochondrial protein that can regulate glucose metabolism through inhibition of pyruvate dehydrogenase complex. An aberrant metabolism is one of the characteristics of cancer cells. In liver cancer, PDK4 has been identified as a potential tumor suppressor [39]. 

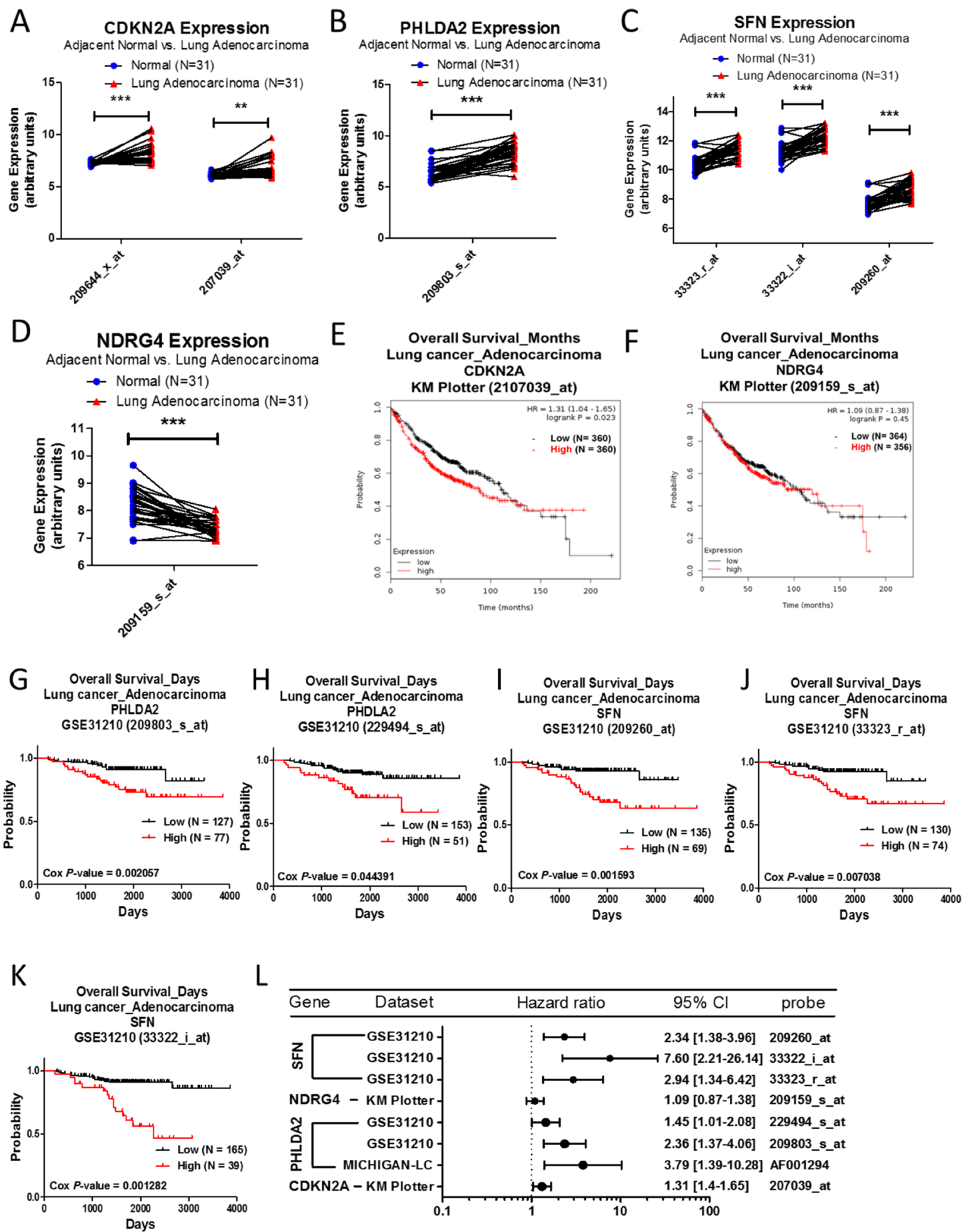

Figure 5: Analysis of CDKN2A, PHLDA2, SFN, and NDRG4 in clinical lung adenocarcinoma patients using bioinformatics databases. The gene expression of CDKN2A (A), PHLDA2 (B), SFN (C), and NDRG4 (D), comparing 31 pairs of clinical lung adenocarcinoma (red) and adjacent normal tissue (blue), was performed on a GSE10072 microarray from the GEO database. The $p$-value of gene expression was calculated by $t$-test with Wilcoxon matched-pairs signed rank test. ${ }^{* * *}$ represents $p<0.001$, ${ }^{* *}$ represents $p<0.01$. The survival curves comparing 2 populations with high (red) and low (black) gene expression in lung adenocarcinoma patients were performed on the Kaplan-Meier plotter database - CDKN2A (E) and NDRG4 (F), and PrognoScan database - PHLDA2 $(\mathbf{G}, \mathbf{H})$ and SFN $(\mathbf{I}-\mathbf{K})$. The analysis criteria of PrognoScan and Kaplan-Meier plotter databases were Cox $p$-value $<0.05$ and log-rank $p$-value $<0.05$ respectively. Raw data of the GEO and PrognoScan databases were extracted and re-plotted by GraphPad Prism 5 software. (L) The forest plots showed hazard ratios (95\% CI, confidence interval) identified from the PrognoScan and Kaplan-Meier plotter databases. 
Table 6: Analysis of AGR2, AQP5, and CLDN3 mRNA expression in lung adenocarcinoma compared to normal tissue from Oncomine database

\begin{tabular}{ccccccc}
\hline Gene & $\begin{array}{c}\text { Fold change } \\
\text { (Cancer/Normal) }\end{array}$ & $\boldsymbol{P}$-value & $\begin{array}{c}\text { Gene Ranking } \\
\text { (Top\%) }\end{array}$ & $\begin{array}{c}\text { Samples } \\
\text { (Normal : Tumor) }\end{array}$ & Dataset & Probe \\
\hline \multirow{6}{*}{ AGR2 } & 2.965 & $9.38 \mathrm{E}-11$ & 6 & $20: 226$ & Okayama & 228969_at \\
& 5.586 & $1.83 \mathrm{E}-15$ & 1 & $25: 25$ & Wei & 209173_at \\
& 2.779 & $9.67 \mathrm{E}-11$ & 7 & $49: 58$ & Landi & 209173_at \\
& 3.434 & $1.49 \mathrm{E}-8$ & 1 & $30: 27$ & Su & 209173_at \\
& 2.902 & 0.003 & 3 & $17: 132$ & Bhattacharjee & 38827_at \\
AQP5 & 2.677 & $1.80 \mathrm{E}-5$ & 6 & $19: 20$ & Stearman & 38827_at \\
& 2.393 & $5.73 \mathrm{E}-11$ & 7 & $58: 58$ & Selamat & ILMN_1814151 \\
& 2.841 & $2.80 \mathrm{E}-6$ & 10 & $25: 25$ & Wei & 213611_at \\
& 3.287 & $5.33 \mathrm{E}-12$ & 4 & $20: 226$ & Okayama & 203954_x_at \\
& 3.594 & $1.50 \mathrm{E}-11$ & 1 & $25: 25$ & Wei & 203954_x_at \\
& 3.282 & $1.71 \mathrm{E}-7$ & 2 & $30: 27$ & Su & 203954_x_at \\
& 2.193 & $4.34 \mathrm{E}-16$ & 2 & $49: 58$ & Landi & 203954_x_at \\
& 3.707 & $1.61 \mathrm{E}-8$ & 1 & $19: 20$ & Stearman & 33904_at \\
& 5.152 & $3.60 \mathrm{E}-5$ & 1 & $17: 132$ & Bhattacharjee & 33904_at \\
& 3.154 & $3.74 \mathrm{E}-14$ & 4 & $58: 58$ & Selamat & ILMN_1723042 \\
\hline
\end{tabular}

Table 7: Analysis of IL33 mRNA expression in lung adenocarcinoma compared to normal tissue from Oncomine database

\begin{tabular}{ccccccc}
\hline Gene & $\begin{array}{c}\text { Fold change } \\
\text { (Cancer/Normal) }\end{array}$ & $\boldsymbol{P}$-value & $\begin{array}{c}\text { Gene Ranking } \\
\text { (Top\%) }\end{array}$ & $\begin{array}{c}\text { Samples } \\
\text { (Normal : Tumor) }\end{array}$ & Dataset & Probe \\
\hline \multirow{6}{*}{$\mathbf{I L 3 3}$} & -3.809 & $6.11 \mathrm{E}-20$ & 1 & $20: 226$ & Okayama & 209821_at \\
& -4.325 & $1.04 \mathrm{E}-9$ & 5 & $25: 25$ & Wei & $209821 \_$at \\
& -3.276 & $1.23 \mathrm{E}-21$ & 2 & $49: 58$ & Landi & $209821 \_$at \\
& -7.088 & $1.82 \mathrm{E}-9$ & 3 & $30: 27$ & Su & $209821 \_$at \\
& -3.582 & $2.02 \mathrm{E}-11$ & 7 & $65: 45$ & Hou & 209821_at \\
& -2.163 & $8.36 \mathrm{E}-5$ & 7 & $17: 132$ & Bhattacharjee & 35333_r_at \\
& -2.351 & $5.08 \mathrm{E}-5$ & 8 & $19: 20$ & Stearman & 35333_r_at \\
& -4.258 & $5.82 \mathrm{E}-30$ & 1 & $58: 58$ & Selamat & ILMN_1809099 \\
\hline
\end{tabular}

Ironically, PDK4 exerts oncogenic effects in colon cancer [40]. In our study, PDK4 played a potential tumor suppressor role in lung adenocarcinoma.

FMO2 is an NADPH-dependent enzyme that catalyzes the oxygenation of substrates [41], but the effect of FMO2 on tumorigenesis is unclear. Although genetic polymorphisms of FMO genes may influence drug metabolism [42], we found that FMO2 might have tumor suppressor effects in lung adenocarcinoma.

FABP4 is involved in fatty acids trafficking and metabolism. Fatty acids serve as both an energy source and signaling molecules that can regulate various cellular functions [43]. The dysfunction of FABP proteins has been found to be associated with some metabolic diseases [44], and elevated FABP4 has been observed in many types of cancer [45-47]. Our data showed that FABP4 may have tumor suppressor effects in lung adenocarcinoma.

CDKN2A encodes two spliced transcripts, $\mathrm{p} 16^{\mathrm{INK} 4 \mathrm{a}}$ and $\mathrm{p} 14^{\mathrm{ARF}}$, which regulate cell cycle progression through inhibition of CDK4 kinase and p53 respectively [48]. CDKN2A has been shown as a tumor suppressor in cancer progression [49], and its alterations, including epigenetic modifications, deletion, and mutations, frequently occur in cancers [50]. In our study, 


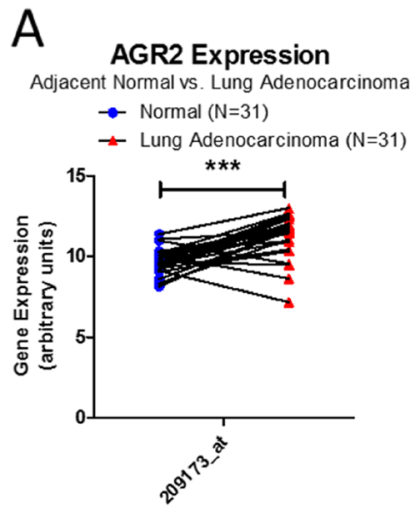

B
CLDN3 Expression
Adjacent Normal vs. Lung Adenocarcinoma
$\rightarrow$ Normal $(\mathrm{N}=31)$

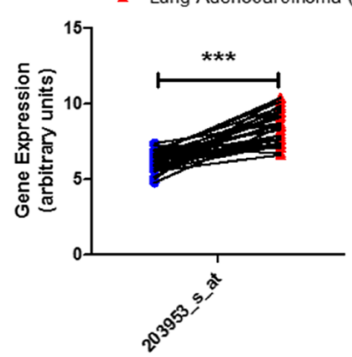

Overall Survival_Months
Lung cancer_Adenocarcinoma KM Plotter (203954_x_at)

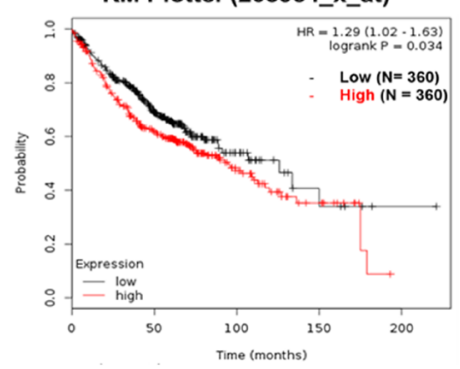

G

Overall Survival_Days Lung cancer_Adenocarcinoma AQP5

GSE31210 (213611_at)

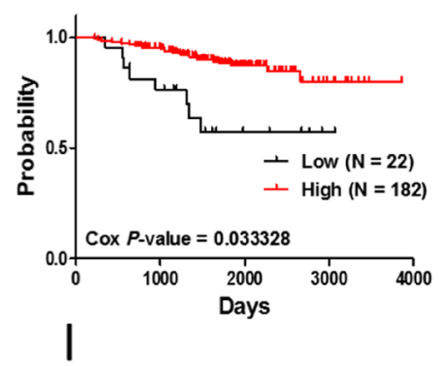

H Overall Survival_Days

Lung cancer_Adenocarcinoma AGR2

GSE31210 (209173_at)

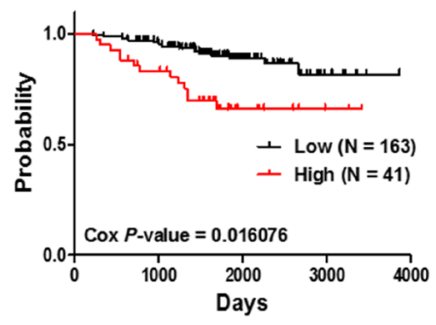

- Lung Adenocarcinoma $(\mathrm{N}=31)$

E Overall Survival_Months Lung cancer_Adenocarcinoma AQP5

C

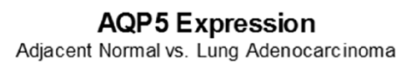

AQP5 Expression

Adjacent Normal vs. Lung Adenocarcinoma

$\rightarrow$ Normal $(\mathrm{N}=31)$

\# Lung Adenocarcinoma ( $N=31)$

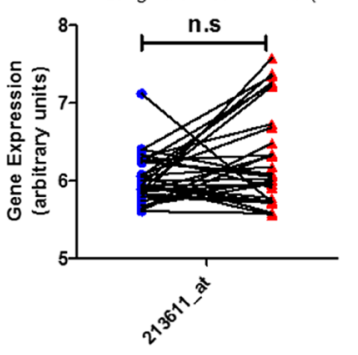

$\mathrm{F}$

Overall Survival_Months Lung cancer Adenocarcinoma

KM Plotter (213611_at)

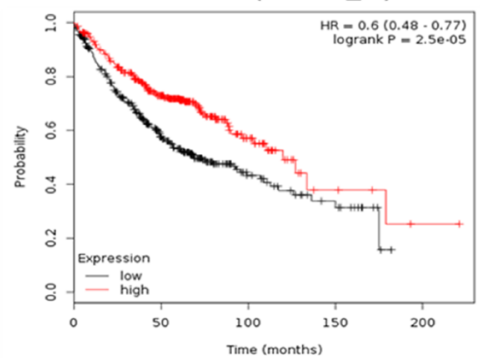

iacob-00182 (213611_at)

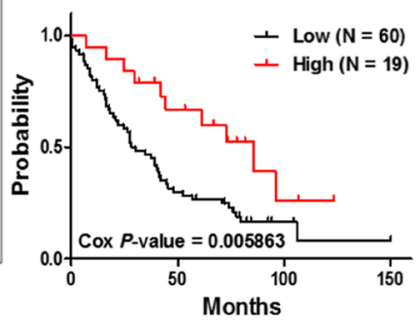

Figure 6: Analysis of AGR2, CLDN3, and AQP5 in clinical lung adenocarcinoma patients using bioinformatics databases. The gene expression of AGR2 (A), CLDN3 (B), and AQP5 (C), comparing 31 pairs of clinical lung adenocarcinoma (red) and adjacent normal tissue (blue), was performed on a GSE10072 microarray from the GEO database. The $p$-value of gene expression was calculated by $t$-test with Wilcoxon matched-pairs signed rank test. ${ }^{* * *}$ represents $p<0.001$ and n.s. represents no significance. Survival curves comparing 2 populations with high (red) and low (black) gene expression in lung adenocarcinoma patients were performed on the Kaplan-Meier plotter - CLDN3 (D) and AQP5 (E), and PrognoScan databases - AQP5 (F, G) and AGR2 (H). The analysis criteria of the PrognoScan and Kaplan-Meier plotter databases were Cox $p$-value $<0.05$ and log-rank $p$-value $<0.05$ respectively. The raw data of the GEO and PrognoScan databases were extracted and re-plotted by GraphPad Prism 5 software. (I) The forest plots showed hazard ratios ( $95 \%$ CI, confidence interval) identified from the PrognoScan and Kaplan-Meier plotter databases. 
CDKN2A may have potential oncogenic effects in lung adenocarcinoma.

PHLDA2, located in an imprinted region on chromosome $11 \mathrm{p} 15.5$, has primarily been studied for its regulation of placental growth [51]. Although the role of PHLDA2 in cancer is unclear, our data showed that
PHLDA2 may potentially exert oncogenic effects in lung adenocarcinoma.

SFN is involved in protein synthesis and epithelial cell growth. Numerous reports have demonstrated the molecular functions of SFN in keratinocytes and fibroblasts [52]. Furthermore, elevated expression of SFN

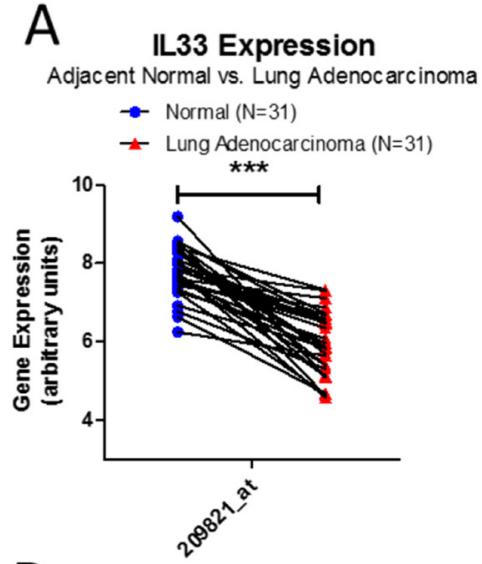

D

Overall Survival_Months Lung cancer_Adenocarcinoma IL33 iacob-00182-MSK (209821_at)

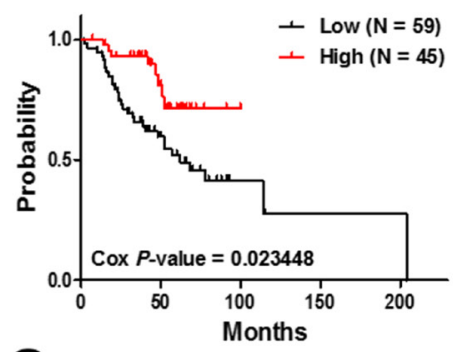

G

Overall Survival_Months Lung cancer_Adenocarcinoma IL33

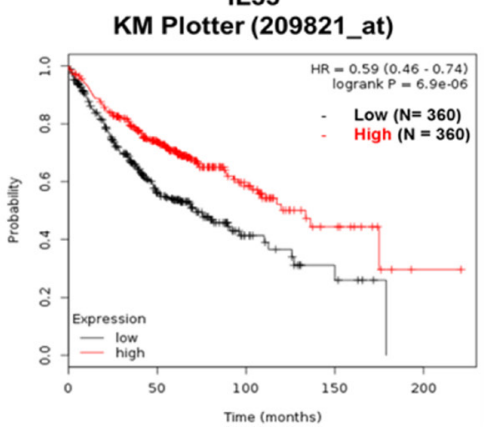

B

CENSORED:SURVIVAL_MONTHS IL33

Lung Adenocarcinoma TCGA (90865)

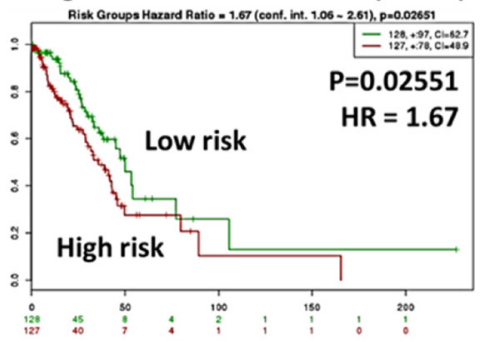

$E$

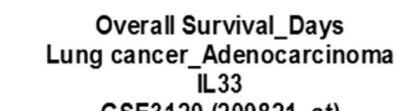

GSE3120 (209821_at)

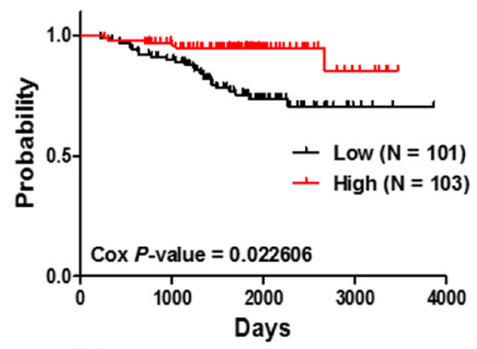

$\mathrm{H}$
C

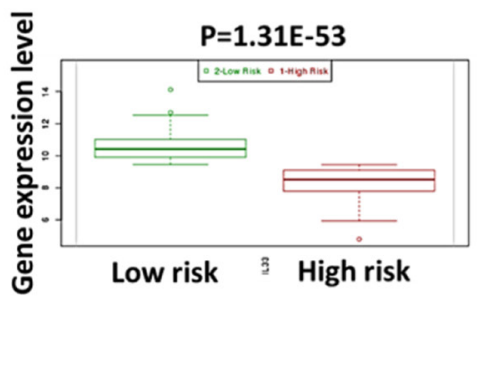

$\mathrm{F}$
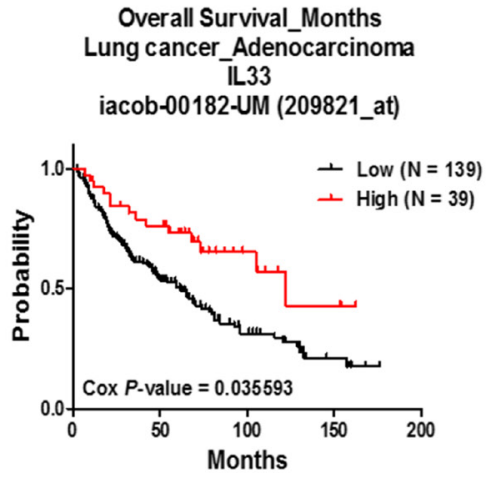

Figure 7: Analysis of IL33 in clinical lung adenocarcinoma patients using bioinformatics databases. The gene expression of IL33 (A), comparing 31 pairs of clinical lung adenocarcinoma (red) and adjacent normal tissue (blue), was performed on a GSE10072 microarray from the GEO database. The $p$-value of gene expression was calculated by $t$-test with Wilcoxon matched-pairs signed rank test. ${ }^{* * *}$ represents $p<0.001$. (B) The survival curve was captured from the SurvExpress database, which divided lung adenocarcinoma patients into 2 populations of high (red) and low (green) risk, and (C) the box plots showed that the high risk (red) population has lower levels of IL33 expression, while the low risk (green) population has higher levels of IL33 expression. (D-F) The survival curves comparing 2 populations with high (red) and low (black) gene expression in lung adenocarcinoma patients were performed on the PrognoScan and (G) Kaplan-Meier plotter databases. The analysis criteria of the PrognoScan and Kaplan-Meier plotter databases were Cox $p$-value $<0.05$ and log-rank $p$-value $<0.05$ respectively. Raw data of the GEO and the PrognoScan databases were extracted and re-plotted by GraphPad Prism 5 software. (H) The forest plots showed hazard ratios (95\% CI, confidence interval) identified from the PrognoScan and Kaplan-Meier plotter databases. 
Table 8: Analysis of ZDHHC9, BTNL9, GNG11 and CPED1 mRNA expression in lung adenocarcinoma compared to normal tissue from Oncomine database

\begin{tabular}{|c|c|c|c|c|c|c|}
\hline Gene & $\begin{array}{c}\text { Fold change } \\
\text { (Cancer/Normal) }\end{array}$ & $P$-value & $\begin{array}{l}\text { Gene Ranking } \\
\text { (Top\%) }\end{array}$ & $\begin{array}{c}\text { Samples } \\
\text { (Normal : Tumor) }\end{array}$ & Dataset & Probe \\
\hline \multirow{3}{*}{ ZDHHC9 } & 2.295 & 8.84E-12 & 5 & $20: 226$ & Okayama & 222451_s_at \\
\hline & 2.621 & $9.16 \mathrm{E}-10$ & 3 & $25: 25$ & Wei & 222451_s_at \\
\hline & 2.377 & $3.27 \mathrm{E}-19$ & 1 & $58: 58$ & Selamat & ILMN_1803824 \\
\hline \multirow{3}{*}{ BTNL9 } & -12.000 & $3.77 \mathrm{E}-14$ & 3 & $20: 226$ & Okayama & 228434_at \\
\hline & -10.916 & $6.99 \mathrm{E}-26$ & 1 & $25: 25$ & Wei & 228434_at \\
\hline & -9.102 & $1.02 \mathrm{E}-24$ & 1 & $65: 45$ & Hou & 228434_at \\
\hline \multirow{9}{*}{ GNG11 } & -3.630 & $9.97 \mathrm{E}-21$ & 1 & $20: 226$ & Okayama & 204115_at \\
\hline & -4.337 & $6.55 \mathrm{E}-11$ & 4 & $25: 25$ & Wei & 204115_at \\
\hline & -3.463 & $1.49 \mathrm{E}-12$ & 1 & $30: 27$ & $\mathrm{Su}$ & 204115_at \\
\hline & -3.277 & $7.32 \mathrm{E}-23$ & 2 & $49: 58$ & Landi & 204115_at \\
\hline & -3.485 & $7.75 \mathrm{E}-11$ & 1 & $19: 20$ & Stearman & 37908_at \\
\hline & -20.213 & $2.51 \mathrm{E}-11$ & 1 & $17: 132$ & Bhattacharjee & 37908_at \\
\hline & -6.202 & $6.90 \mathrm{E}-25$ & 2 & $58: 58$ & Selamat & ILMN_1782419 \\
\hline & -2.830 & $4.15 \mathrm{E}-11$ & 3 & $10: 86$ & Beer & U31384_at \\
\hline & -4.296 & $3.94 \mathrm{E}-4$ & 4 & $5: 5$ & Wachi & 204115_at \\
\hline \multirow{3}{*}{ CPED1 } & -2.181 & $7.18 \mathrm{E}-14$ & 2 & $25: 25$ & Wei & 220032_at \\
\hline & -3.108 & $1.13 \mathrm{E}-17$ & 2 & $65: 45$ & Hou & 228728_at \\
\hline & -3.325 & $1.03 \mathrm{E}-34$ & 1 & $58: 58$ & Selamat & ILMN_1677038 \\
\hline
\end{tabular}

has been reported in lung adenocarcinoma [53], and our study also found that SFN may exert oncogenic effects in lung adenocarcinoma.

NDRG4 is involved in the regulation of cell cycle progression [54] and has been identified as a novel tumor suppressor in colon cancer [55]. We found that NDRG4 levels were significantly decreased in lung adenocarcinoma, but with regard to survival analysis, the expression of NDRG4 has shown no significant influence on survival rates of lung cancer patients.

AGR2 is an endoplasmic reticulum (ER) protein which can catalyze protein folding. Its oncogenic role and increased expression have been reported in different types of cancer [56-58]. In our study, we found that AGR2 may serve as a potential prognostic biomarker of lung adenocarcinoma.

$\mathrm{AQP} 5$, aquaporin 5 , is a water channel protein involved in pulmonary secretions, and elevated expression of AQP5 is associated with poor survival outcome in many types of cancer [59-61]. In our study, the expression of AQP5 was upregulated in lung adenocarcinoma, and its high expression correlated with better survival outcome.

CLDN3 regulates tight junctions of cell-cell adhesion in epithelial or endothelial cells and is overexpressed in ovarian [62] and colon cancer [63]. Loss of claudin 3 expression increases the metastatic ability of esophageal cancer [64], whereas claudin 3 is upregulated in lung adenocarcinoma [65]. Our study showed that claudin 3 may have oncogenic effects in lung adenocarcinoma.

IL33 is a cytokine involved in a spectrum of biological processes, and the chronic inflammatory signaling activation is known to be involved in cancer progression. The expression of IL33 in tumor tissues is depressed, but tumor stroma and serum have increased levels of IL33, suggesting the distinct functions of IL33 in cancer cells from the microenvironment [66]. IL-33 is shown to promote tumorigenesis and induce stemness in breast cancer [67]. In $\mathrm{Apc}^{\mathrm{Min} /+}$ mice, epithelial-derived IL-33 can promote intestinal tumorigenesis [68]. These reports indicated the function of IL-33 in tumorigenesis is controversial. In our analysis, we found that IL33 may have tumor suppressor functions in lung adenocarcinoma.

ZDHHC9 is a palmitoyltransferase that can regulate palmitoylation of HRAS and NRAS. The function of ZDHHC9 in cancers is unclear, although inactivation of ZDHHC9 can reduce leukemogenic effects through repression of oncogenic NRAS [69]. According to our data, increased ZDHHC9 is observed in lung adenocarcinoma, but its high expression is correlated with better rates of survival.

BTNL9 belongs to the immunoglobulin superfamily, with the butyrophilin family modulating immune homeostasis [70]. Although the function of BTNL9 in tumorigenesis remains unclear, our results suggest that BTNL9 may serve as a tumor suppressor. 

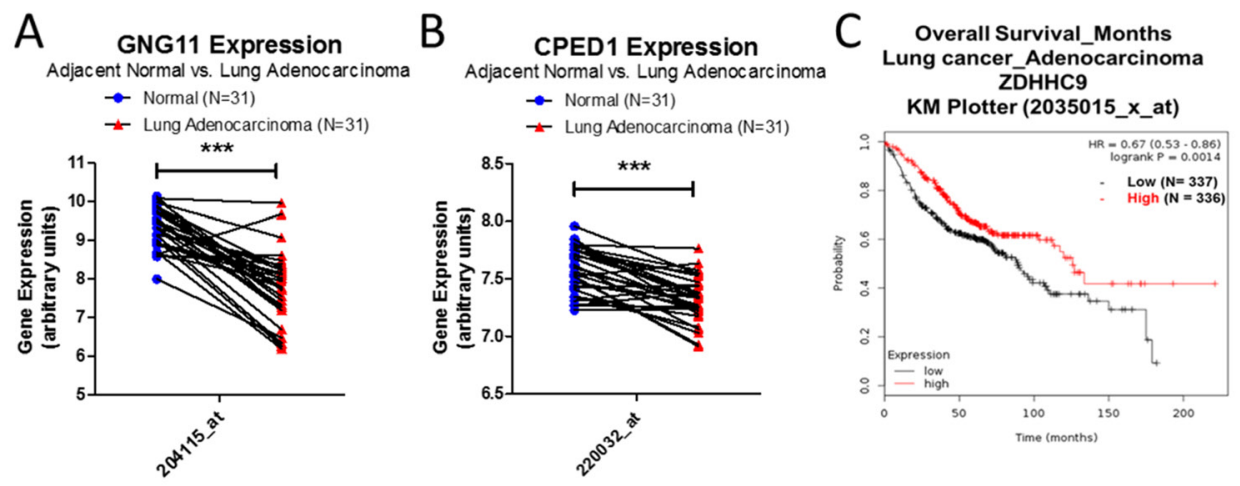
D Overall Survival_Months Lung cancer_Adenocarcinoma BTNL9

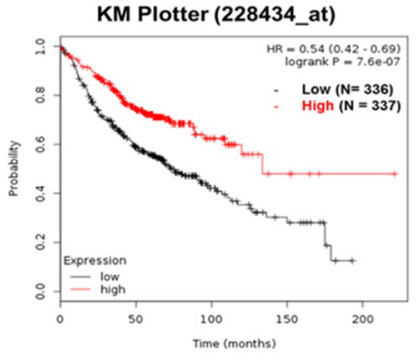 E $\begin{gathered}\text { Overall Survival_Days } \\ \text { Lung cancer_Adenocarcinoma }\end{gathered}$ BTNL9

GSE31210 (1553279_at)
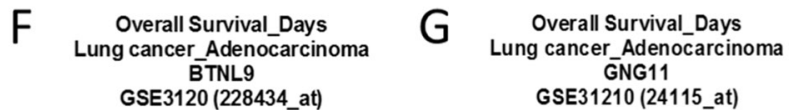
GSE31210 (24115_at)
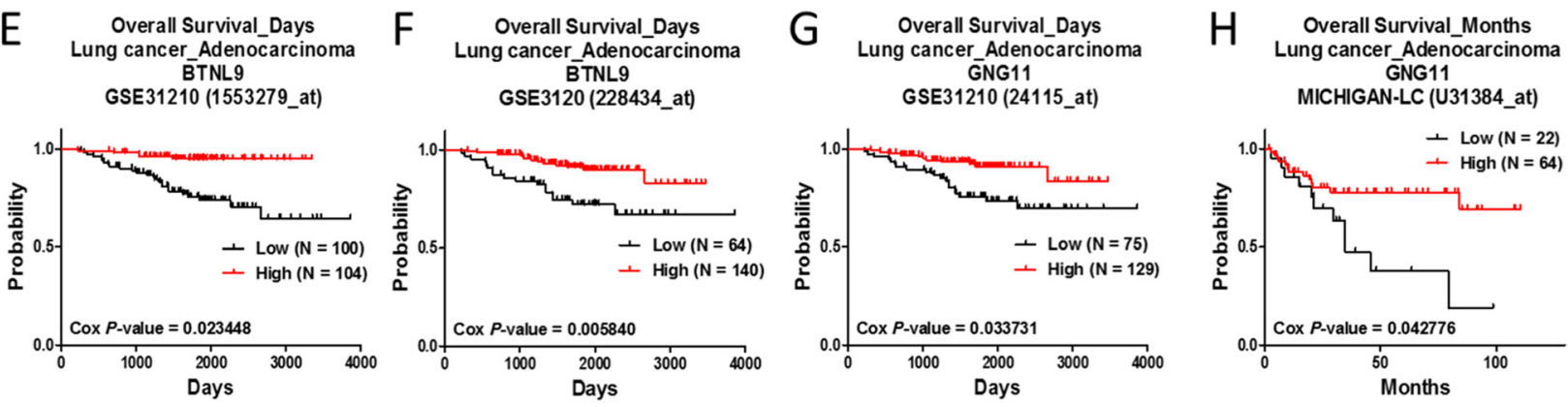
MICHIGAN-LC (U31384_at)
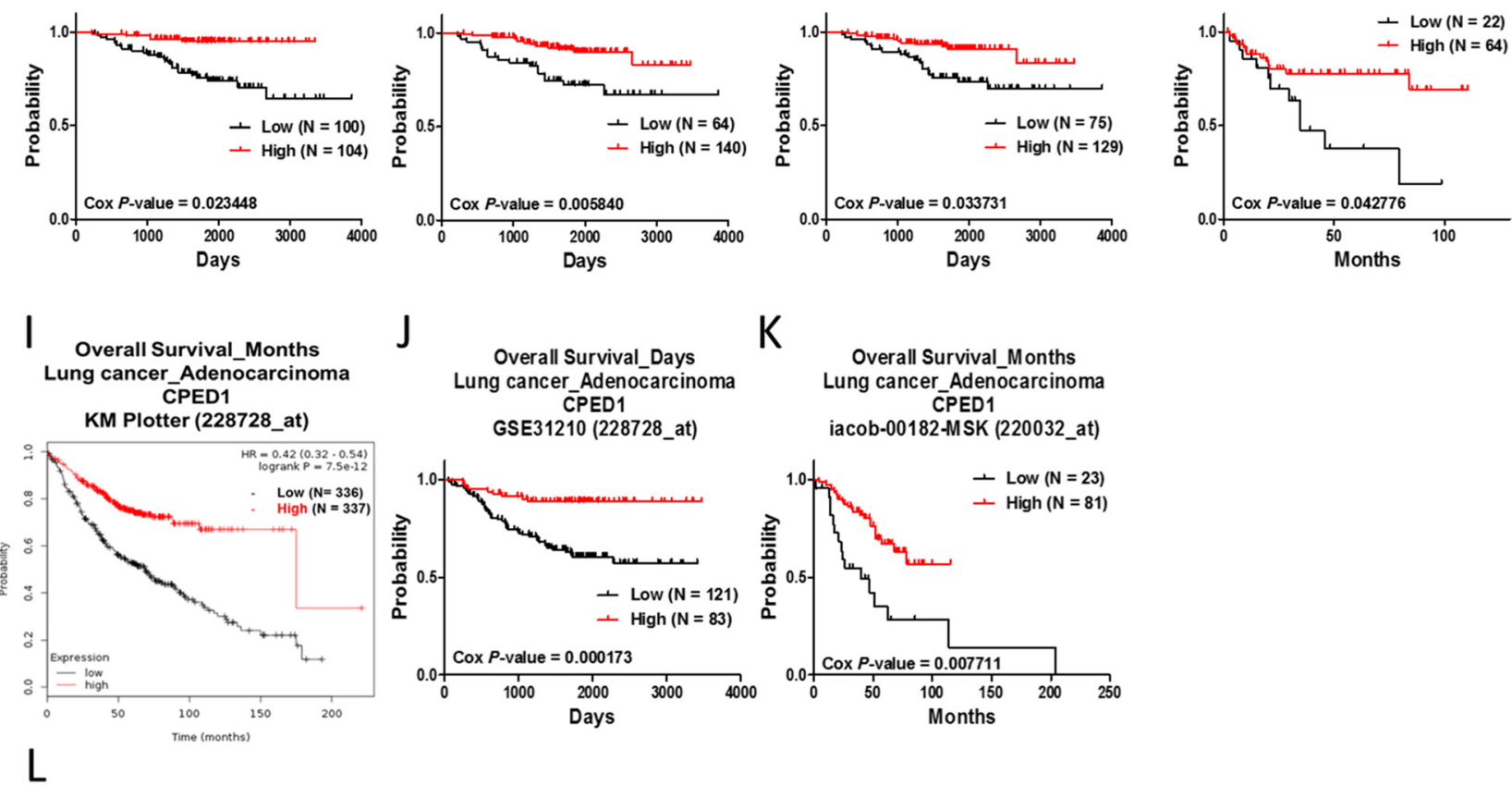

\section{K} Overall Survival_Months
Lung cancer_Adenocarcinoma
CPED1
iacob-00182-MSK (220032 at)
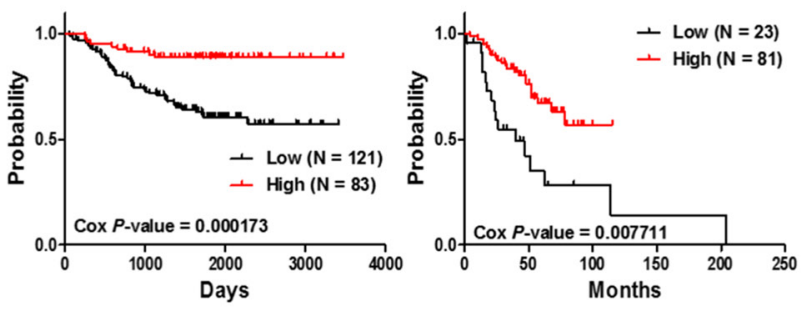

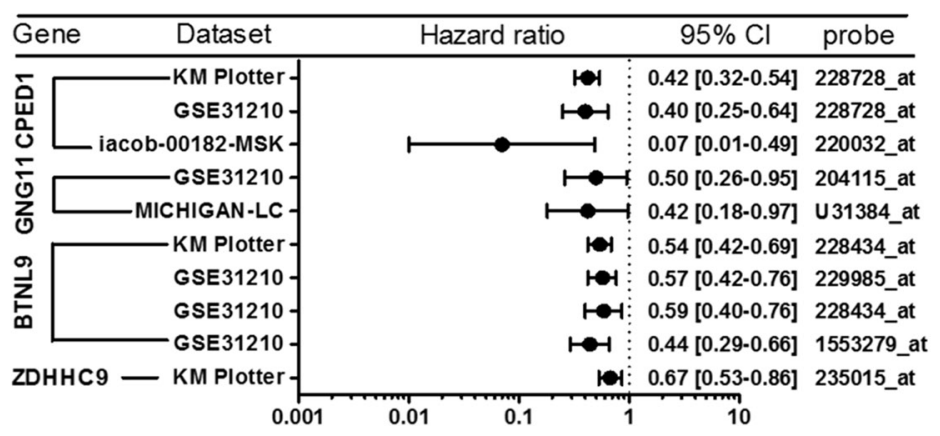

Figure 8: Analysis of ZDHHC9, BTNL9, GNG11 and CPED1 in clinical lung adenocarcinoma patients using bioinformatics databases. The gene expression of GNG11 (A) and CPED1 (B), comparing 31 pairs of clinical lung adenocarcinoma (red) and adjacent normal tissue (blue), was performed on a GSE10072 microarray from the GEO database. The $p$-value of gene expression was calculated by $t$-test with Wilcoxon matched-pairs signed rank test. ${ }^{* * *}$ represents $p<0.001$. The survival curves comparing 2 populations with high (red) and low (black) gene expression in lung adenocarcinoma patients were performed on the Kaplan-Meier plotter database ZDHHC9 (C), BTNL9 (D) and CPED1 (I), and the PrognoScan database - BTNL9 (E, F), GNG11 (G, H), and CPED1 (J, K). The analysis criteria of the PrognoScan and Kaplan-Meier plotter databases were Cox $p$-value $<0.05$ and $\log$-rank $p$-value $<0.05$ respectively. Raw data of the GEO and PrognoScan databases were extracted and re-plotted by GraphPad Prism 5 software. (L) The forest plots showed hazard ratios (95\% CI, confidence interval) identified from the PrognoScan and Kaplan-Meier plotter databases. 
Table 9: Differentially expressed microRNAs identified from next-generation sequencing data

\begin{tabular}{|c|c|c|c|c|c|c|c|c|}
\hline \multirow{2}{*}{ miRNAs } & \multirow{2}{*}{ Precursor } & \multicolumn{6}{|c|}{ RPM (Reads per million) } & \multirow{2}{*}{$\mathbf{T} / \mathbf{N}$} \\
\hline & & N1 & T1 & N2 & $\mathrm{T} 2$ & N3 & T3 & \\
\hline hsa-miR-1307-5p & hsa-mir-1307 & 118.34 & 396.09 & 109.76 & 504.13 & 28.34 & 66.54 & Up \\
\hline hsa-miR-130b-5p & hsa-mir-130b & 2.31 & 12.19 & 1.71 & 5.58 & 1.29 & 3.25 & Up \\
\hline hsa-miR-130b-3p & hsa-mir-130b & 15.6 & 132.83 & 14.09 & 64.85 & 13.7 & 29.88 & $\mathrm{Up}$ \\
\hline hsa-miR-182-5p & hsa-mir-182 & 926.7 & 5350.27 & 731.46 & 5334.41 & 1779.57 & 15146.54 & Up \\
\hline hsa-miR-183-5p & hsa-mir-183 & 179.58 & 1197.91 & 111.57 & 917.47 & 471 & 2525.39 & $\mathrm{Up}$ \\
\hline hsa-miR-190a-5p & hsa-mir-190a & 6.7 & 30.48 & 11 & 26.46 & 2.76 & 6.5 & Up \\
\hline hsa-miR-200a-5p & hsa-mir-200a & 7.4 & 28.83 & 7.05 & 87.67 & 10.08 & 36.2 & Up \\
\hline hsa-miR-200b-3p & hsa-mir-200b & 459.71 & 1338.61 & 275.25 & 2046.74 & 245.19 & 494.41 & Up \\
\hline hsa-miR-21-3p & hsa-mir-21 & 472.88 & 2282.29 & 448.1 & 7108.65 & 312.3 & 862.23 & Up \\
\hline hsa-miR-224-5p & hsa-mir-224 & 15.95 & 85.34 & 17.72 & 150.97 & 15.16 & 68.89 & Up \\
\hline hsa-miR-301b-3p & hsa-mir-301b & 4.74 & 173.22 & 6.41 & 22.7 & 2.76 & 8.49 & Up \\
\hline hsa-miR-31-5p & hsa-mir-31 & 91.18 & 452.09 & 5.98 & 65.76 & 5.17 & 55.44 & $\mathrm{Up}$ \\
\hline hsa-miR-33b-5p & hsa-mir-33b & 5.78 & 20.57 & 5.45 & 51.23 & 2.5 & 10.56 & Up \\
\hline hsa-miR-345-5p & hsa-mir-345 & 34.44 & 97.53 & 28.29 & 178.85 & 54.97 & 139.04 & Up \\
\hline hsa-miR-424-3p & hsa-mir-424 & 2.43 & 30.22 & 4.38 & 47.34 & 2.5 & 10.38 & Up \\
\hline hsa-miR-424-5p & hsa-mir-424 & 35.82 & 240.9 & 34.27 & 164.07 & 17.83 & 54.17 & $\mathrm{Up}$ \\
\hline hsa-miR-429 & hsa-mir-429 & 143.41 & 407.01 & 153.53 & 673.9 & 119.92 & 359.34 & Up \\
\hline hsa-miR-450a-5p & hsa-mir-450a-1 & 4.39 & 25.53 & 5.87 & 28.4 & 2.93 & 8.67 & Up \\
\hline hsa-miR-450a-5p & hsa-mir-450a-2 & 4.39 & 25.4 & 5.87 & 28.27 & 2.93 & 8.67 & Up \\
\hline hsa-miR-452-5p & hsa-mir-452 & 11.79 & 36.95 & 23.81 & 72.5 & 20.16 & 45.05 & Up \\
\hline hsa-miR-542-3p & hsa-mir-542 & 11.33 & 54.23 & 13.99 & 60.05 & 7.41 & 34.67 & Up \\
\hline hsa-miR-7705 & hsa-mir-7705 & 3 & 14.6 & 4.91 & 28.4 & 3.27 & 7.4 & Up \\
\hline hsa-miR-96-5p & hsa-mir-96 & 25.31 & 64 & 13.77 & 55.25 & 19.82 & 204.5 & $\mathrm{Up}$ \\
\hline
\end{tabular}

GNG11 is a lipid-anchored protein, which has been reported to inhibit cell growth [71] and regulate cellular senescence in lymphoma [72]. We found that GNG11 may exert suppressor functions in the tumorigenesis of lung adenocarcinoma.

CPED1, also known as C7orf58, contains a cadherin-like beta sandwich domain [73], but the molecular function of CPED1 is unclear. Our data showed that CPED1 may play a role as a potential tumor suppressor in lung adenocarcinoma.

The summary of differentially expressed genes in the Oncomine database is shown in Supplementary Table 3. Seven of a total of 11 datasets showed similar patterns of genetic expression, suggesting that this molecular change is constant between lung adenocarcinoma and normal lung tissue. Thus, those genes found in this study may represent a novel gene expression signature in lung adenocarcinoma (Figure 10). The increased expression of AGR2 and decreased expression of IL33 have also been identified in other reports. We also analyzed the expression of microRNAs in lung adenocarcinoma (Table 9). Twenty-too upregulated microRNAs were identified in lung adenocarcinoma. We focused on microRNAs with predictable putative targets - BTNL9, FMO2, IL33, CPED1, and PDK4. Among these microRNAs, elevated expression of hsa-miR-183-5p [74], hsa-miR-33b-5p [75], hsa-miR-429 [76], hsa-miR-182-5p [77], and hsa-miR$130 \mathrm{~b}-5 \mathrm{p}$ [78] have been associated with tumorigenesis in lung cancer. The function of hsa-miR-542-3p is unclear. However, since the genetic interactions of hsa-miR-1835p-BTNL9, hsa-miR-33b-5p-CPED1, hsa-miR-429CPED1, hsa-miR-182-5p-FMO2, hsa-miR-130b-5p-IL33, and hsa-miR-542-3p-IL33 have not been identified, these altered genetic regulations may play important roles in the progression of lung adenocarcinoma.

\section{MATERIALS AND METHODS}

\section{Clinical lung adenocarcinoma specimens}

Three pairs of tumors and adjacent non-tumor lung tissues were collected from the Division of Thoracic surgery and Division of Pulmonary and Critical Care Medicine, Kaohsiung Medical University Hospital (KMUH), Kaohsiung, Taiwan. Approval for these studies was obtained from the Institutional Review Board (IRB) 
A

$\operatorname{microRNA}(U p>2, \mathrm{RPM}>1)$

Patient 1

Patient 2

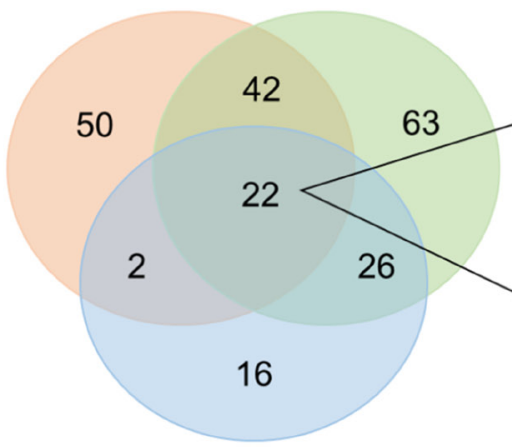

Patient 3

C

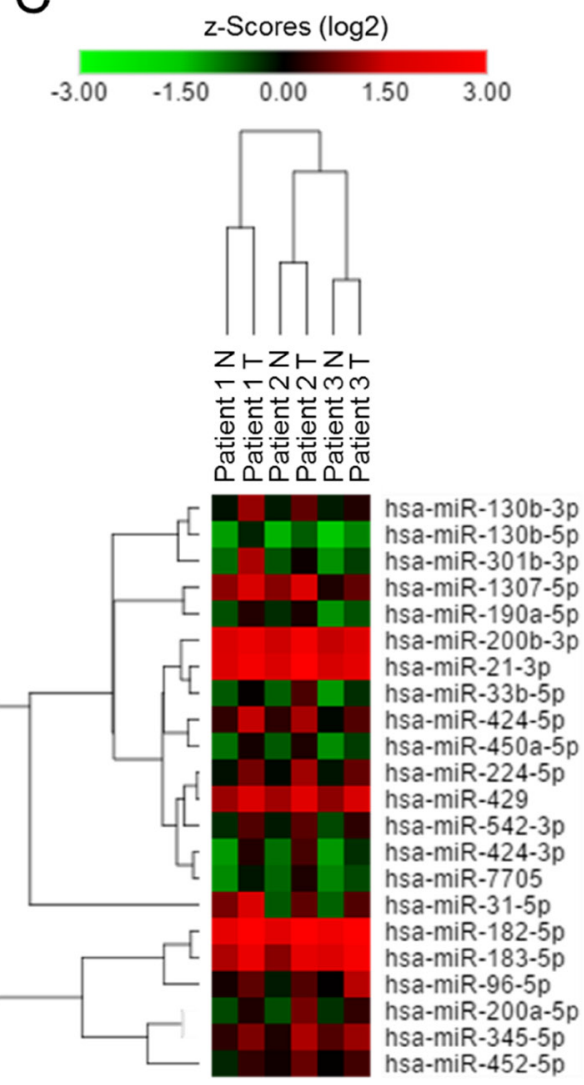

B

microRNA (Down $>2$, RPM $>1)$

Patient 1

hsa-miR-1307-5p hsa-miR-130b-5p

hsa-miR-130b-3p hsa-miR-182-5p hsa-miR-183-5p hsa-miR-190a-5p hsa-miR-200a-5p hsa-miR-200b-3p hsa-miR-21-3p hsa-miR-224-5p hsa-miR-301b-3p hsa-miR-31-5p hsa-miR-33b-5p hsa-miR-345-5p hsa-miR-424-3p hsa-miR-424-5p hsa-miR-429 hsa-miR-450a-5p hsa-miR-452-5p hsa-miR-542-3p hsa-miR-7705

hsa-miR-96-5p

D
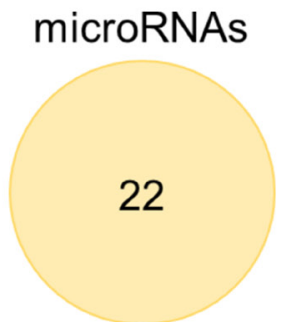

$(U p>2$, RPM $>1)$

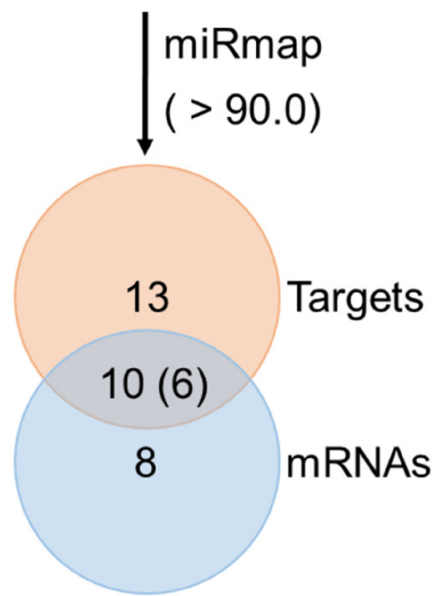

(Down $>2$, FPKM $>0.3$ )

Figure 9: Identification of differentially expressed microRNAs in lung adenocarcinoma compared to adjacent normal tissue using next-generation sequencing. Venn diagram analysis showed 22 upregulated microRNAs (A) and 0 downregulated microRNAs (B) in lung adenocarcinoma, compared to adjacent normal tissue from 3 pairs of clinical specimens. The criteria were fold change $>2$ (tumor/normal) and reads per million $(\mathrm{RPM})>1$. (C) The heatmap diagram showed the differentially expressed genes with $\mathrm{z}$-score $(\log 2)$ values by using color clustering on the GENE-E web-tool. Green represents downregulation (minimum $=-3.0$ ), and red represents upregulation (maximum =3.0). (D) The "Targets" Venn diagram shows the predicted genes of microRNAs from the "microRNAs" Venn diagram using the miRmap web-site database. The selection threshold was miRmap score $\geq 90.0$. The intersection Venn diagram between "mRNAs" and "Targets" showed total of 6 potential microRNA-mRNA interactions. 
Table 10: Genes selected between differentially expressed genes and putative targets of microRNA

\begin{tabular}{ccc}
\hline miRNA & Predicted targets & miRmap score \\
\hline hsa-miR-183-5p & BTNL9 & 92.2457 \\
hsa-miR-200b-3p & CPED1 & 97.3127 \\
hsa-miR-33b-5p & CPED1 & 91.5414 \\
hsa-miR-429 & CPED1 & 97.7498 \\
hsa-miR-182-5p & FMO2 & 98.0884 \\
hsa-miR-345-5p & FMO2 & 96.6797 \\
hsa-miR-130b-5p & IL33 & 98.1906 \\
hsa-miR-542-3p & IL33 & 96.593 \\
hsa-miR-21-3p & NDRG4 & 95.067 \\
hsa-miR-424-5p & PDK4 & 99.1986 \\
\hline
\end{tabular}

of KMUH, and informed consent was obtained from all patients in accordance with the Declaration of Helsinki.

\section{Next-generation sequencing (NGS)}

The expression profile of mRNA and microRNA was performed using NGS [22]. Three pairs of lung adenocarcinomas and adjacent normal specimens were used in this project. Total RNA was extracted by using Trizol ${ }^{\circledR}$ Reagent (Invitrogen, USA), according to the manufacturer's instructions. The cell lysates were applied to Welgene Biotechnology Company (Welgene, Taipei, Taiwan) for RNA-seq and small RNA-seq analysis. The criteria for differentially expressed mRNA analysis were fold change $>2$ and fragments per kilobase million $($ FPKM $)>0.3$. The criteria for differentially expressed microRNAs' selection were fold change $>2$ and reads per million $(\mathrm{RPM})>1$.

\section{Oncomine database analysis}

The Oncomine database contains over 18,000 microarray experiments and 35 major cancer types [23]. The raw data of mRNA expression in clinical lung adenocarcinoma and normal specimens (cancer vs. normal) were extracted from the Oncomine database (http://www.oncomine.org, Compendia biosciences, Ann Arbor, MI, USA). The criteria in the analysis were $P$-value $<1$ E- 4 , fold change $>2$, and gene rank in top $10 \%$. $P$-value was calculated using the Oncomine database through two-sided Student's $t$-test. For the comparison of genes in each dataset, raw data was extracted and replotted using the GENE-E web-tool (https://software. broadinstitute.org/GENE-E/), and the relative color scheme was used for clustering as minimum $=0$ (blue) and maximum $=1$ (yellow). Eleven datasets were selected
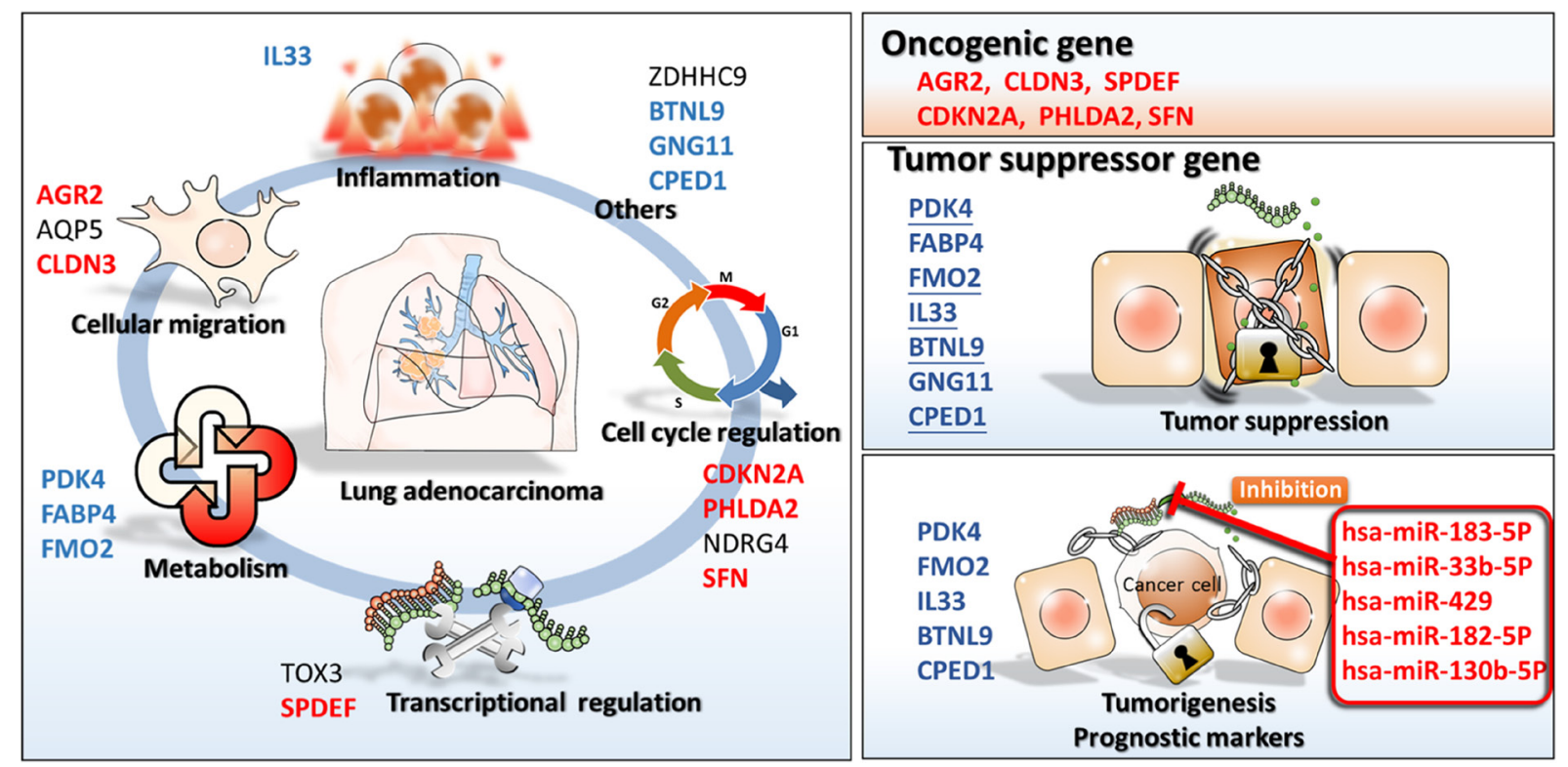

Figure 10: The proposed novel molecular signatures of gene regulations involved in lung adenocarcinoma. 
for our analysis, including Hou (normal = 65 and lung adenocarcinoma $=45$ ) [79], Landi (normal $=49$ and lung adenocarcinoma $=58)[80]$, Selamat $($ normal $=58$ and lung adenocarcinoma $=58)[81]$, Okayama $($ normal $=20$ and lung adenocarcinoma $=226)[82], \mathrm{Su}($ normal $=30$ and lung adenocarcinoma $=27)[83]$, Wei $($ normal $=25$ and lung adenocarcinoma $=25$ )[84], Stearman (normal $=19$ and lung adenocarcinoma $=20)$ [85], Bhattacharjee (normal $=17$ and lung adenocarcinoma $=132$ ) [86], Beer (normal $=10$ and lung adenocarcinoma $=86$ ) [87], Garber (normal $=5$ and lung adenocarcinoma $=40$ ) [88], and Wachi (normal $=5$ and lung adenocarcinoma $=5$ ) [89].

\section{SurvExpress database analysis}

SurvExpress integrates the TCGA database (https:// tcga-data.nci.nih.gov) which provides microarray information, including cancer type, survival, and gene expression. The correlation between IL33 mRNA expression and survival rate was analyzed on the SurvExpress web-databse (http://bioinformatica.mty. itesm.mx/SurvExpress). The dataset lung adenocarcinoma TCGA $(N=255)$ was used in our analysis. Samples of each dataset were split into 2 risk groups (high and low risk) of the same size, of which each group was determined by the ordered Prognostic Index (PI, high value for high risk) [27]. Prognostic Index (PI) is the linear component of the Cox model, computed by gene expression value multiplied with values estimated from the Cox fitting [90].

\section{PrognoScan database analysis}

PrognoScan collects information of the GEO (Gene Expression Omnibus) microarray database, including cancer type, survival rates, and gene expression. The correlation between gene expression and overall survival rates was performed on the PrognoScan web-databse (http://www.abren.net/PrognoScan/) [25]. The raw data were extracted and re-plotted by GraphPad Prism 5 software (GraphPad Software, La Jolla, CA, USA). The threshold was determined as Cox $p$-value $<0.05$. Samples of each dataset were divided into 2 expression groups (high and low) at the potential cutpoint. The cutpoint (from $<0.1$ or $>0.9$ quantile) was estimated by the minimum $P$-value approach [91], and the $P$-value correlation was calculated by the formula [92]. The hazard ratios $(95 \%$ confidence intervals) of each dataset was calculated using the Cox proportional model, and are listed in the related Tables. HR $=0$ represents no difference between 2 groups, $\mathrm{HR}<1$ represents better survival rate in the population with higher levels of expression, and HR $>1$ represents better survival rates in the population with lower levels of expression. The specific probe of each dataset is listed in its related Figure.

\section{Kaplan-Meier plotter database analysis}

The Kaplan-Meier plotter is a web-database providing the information on 54675 genes' expression and survival rates in 10461 cancer samples, including 5143 breast, 1816 ovarian, 2437 lung, and 1065 gastric cancer patients [26]. The correlation of gene expression and overall survival rates in lung cancer was determined, and lung adenocarcinoma $(N=720)$ was selected in our analysis. Patients were split into 2 populations with the best cut-off, which was computed with median survival. The hazard ratios (95\% confidence intervals) were calculated using the Cox proportional model, and are listed in the related Tables. The specific probe of each dataset was listed in its related Figure.

\section{Gene expression omnibus (GEO) database analysis}

GEO is a web-database providing submitted high throughput gene expression data of microarrays, chips, or NGS (https://www.ncbi.nlm.nih.gov/geo/) [24]. We selected the microarray with accession number GSE10072, published in 2008 [80], for this project. This microarray provides gene expression information of 180 clinical lung adenocarcinoma and non-tumor samples. Here, we selected 31 pairs of lung adenocarcinoma with adjacent normal tissue for gene expression analysis. The raw data were analyzed and extracted from GEO2R (https://www. ncbi.nlm.nih.gov/geo/geo2r/), and re-plotted by GraphPad prism 5 software (GraphPad Software, La Jolla, CA, USA). The $p$-value was calculated by using $t$-test with Wilcoxon matched-pairs signed rank test.

\section{miRmap database analysis}

miRmap is a web-tool database providing analysis of microRNA targets prediction (http://mirmap.ezlab. org/) [28]. It identifies the putative target genes by calculating the complementary ability of microRNAmRNA interactions. The strength of mRNA repression is estimated for ranking potential candidate targets by employing various features, including thermodynamic, evolutionary, probabilistic or sequence-based features. The prediction results show a list of putative target genes with miRmap scores, which are a predictive reference values. Putative targets with miRmap scores $\geq 90.0$ were selected for this project.

\section{Statistical analysis}

The raw data extracted from GEO database were statistically analyzed using $t$-test with Wilcoxon matchedpairs signed rank test by GraphPad Prism 5 software (GraphPad Software, La Jolla, CA, USA). 


\section{ACKNOWLEDGMENTS AND FUNDING}

This study was supported by grants from the Ministry of Science and Technology (MOST 106-2314B-037-064; MOST 104-2320-B-037-014-MY3; MOST 104-2314-B-037-053-MY4; MOST 103-2320-B-037006-MY3), the Kaohsiung Medical University "Aim for the Top 500 Universities Grant" (Grant No. KMUTP105C05), the Kaohsiung Medical University "Aim for the Top Journals Grant” (Grant No. KMU-DT106005), and the Kaohsiung Medical University Hospital Research Foundation (KMUH106-6R13).

\section{CONFLICTS OF INTEREST} interest.

The authors declare that they have no conflicts of

\section{REFERENCES}

1. Siegel RL, Miller KD, Jemal A. Cancer Statistics, 2017. CA Cancer J Clin. 2017; 67:7-30.

2. Cooper G. The Cell: A Molecular Approach, 2nd edn. The Cell: A Molecular Approach. Sunderland, MA. USA: Sinauer Associates. 2000.

3. Molina JR, Yang P, Cassivi SD, Schild SE, Adjei AA. Nonsmall cell lung cancer: epidemiology, risk factors, treatment, and survivorship. Mayo Clin Proc. 2008; 83:584-594.

4. Goldstraw P, Ball D, Jett JR, Le Chevalier T, Lim E, Nicholson AG, Shepherd FA. Non-small-cell lung cancer. Lancet. 2011; 378:1727-1740.

5. Ridge CA, McErlean AM, Ginsberg MS. Epidemiology of lung cancer. Semin Intervent Radiol. 2013; 30:93-98.

6. Uramoto H, Tanaka F. Recurrence after surgery in patients with NSCLC. Transl Lung Cancer Res. 2014; 3:242-249.

7. Consonni D, Pierobon M, Gail MH, Rubagotti M, Rotunno M, Goldstein A, Goldin L, Lubin J, Wacholder S, Caporaso NE, Bertazzi PA, Tucker MA, Pesatori AC, et al. Lung cancer prognosis before and after recurrence in a populationbased setting. J Natl Cancer Inst. 2015; 107:djv059.

8. Tsvetkova E, Goss GD. Drug resistance and its significance for treatment decisions in non-small-cell lung cancer. Curr Oncol. 2012; 19:S45-S51.

9. Morgillo F, Della Corte CM, Fasano M, Ciardiello F. Mechanisms of resistance to EGFR-targeted drugs: lung cancer. ESMO Open. 2016; 1:e000060.

10. Chen XF, Zhang YW, Xu H, Bu G. Transcriptional regulation and its misregulation in Alzheimer's disease. Mol Brain. 2013; 6:44.

11. Torgovnick A, Schumacher B. DNA repair mechanisms in cancer development and therapy. Front Genet. 2015; 6:157.

12. Wikman H, Kettunen E. Regulation of the G1/S phase of the cell cycle and alterations in the RB pathway in human lung cancer. Expert Rev Anticancer Ther. 2006; 6:515-530.
13. Shivapurkar N, Reddy J, Chaudhary PM, Gazdar AF. Apoptosis and lung cancer: a review. J Cell Biochem. 2003; 88:885-898.

14. Martin TA, Ye L, Sanders AJ, Lane J, Jiang WG. (2013). Cancer invasion and metastasis: molecular and cellular perspective. In: Madame Curie Bioscience database (Austin (TX): Landes Bioscience).

15. Davidson SM, Papagiannakopoulos T, Olenchock BA, Heyman JE, Keibler MA, Luengo A, Bauer MR, Jha AK, O'Brien JP, Pierce KA, Gui DY, Sullivan LB, Wasylenko TM, et al. Environment Impacts the Metabolic Dependencies of Ras-Driven Non-Small Cell Lung Cancer. Cell Metab. 2016; 23:517-528.

16. Moorthy B, Chu C, Carlin DJ. Polycyclic aromatic hydrocarbons: from metabolism to lung cancer. Toxicol Sci. 2015; 145:5-15.

17. Baldi A, De Luca A, Esposito V, Campioni M, Spugnini EP, Citro G. Tumor suppressors and cell-cycle proteins in lung cancer. Patholog Res Int. 2011; 2011:605042.

18. El-Telbany A, Ma PC. Cancer genes in lung cancer: racial disparities: are there any? Genes Cancer. 2012; 3:467-480. https://doi.org/10.1177/1947601912465177.

19. Gulyaeva LF, Kushlinskiy NE. Regulatory mechanisms of microRNA expression. J Transl Med. 2016; 14:143.

20. Ortholan C, Puissegur MP, Ilie M, Barbry P, Mari B, Hofman P. MicroRNAs and lung cancer: new oncogenes and tumor suppressors, new prognostic factors and potential therapeutic targets. Curr Med Chem. 2009; 16:1047-1061.

21. Croce CM. Causes and consequences of microRNA dysregulation in cancer. Nat Rev Genet. 2009; 10:704-714.

22. Zhao M, Liu D, Qu H. Systematic review of next-generation sequencing simulators: computational tools, features and perspectives. Brief Funct Genomics. 2017; 16:121-128.

23. Rhodes DR, Kalyana-Sundaram S, Mahavisno V, Varambally R, Yu J, Briggs BB, Barrette TR, Anstet MJ, Kincead-Beal C, Kulkarni P, Varambally S, Ghosh D, Chinnaiyan AM. Oncomine 3.0: genes, pathways, and networks in a collection of 18,000 cancer gene expression profiles. Neoplasia. 2007; 9:166-180.

24. Clough E, Barrett T. The Gene Expression Omnibus Database. Methods Mol Biol. 2016; 1418:93-110.

25. Mizuno H, Kitada K, Nakai K, Sarai A. PrognoScan: a new database for meta-analysis of the prognostic value of genes. BMC Med Genomics. 2009; 2:18.

26. Szasz AM, Lanczky A, Nagy A, Forster S, Hark K, Green JE, Boussioutas A, Busuttil R, Szabo A, Gyorffy B. Cross-validation of survival associated biomarkers in gastric cancer using transcriptomic data of 1,065 patients. Oncotarget. 2016; 7:49322-49333. https://doi.org/10.18632/ oncotarget.10337.

27. Aguirre-Gamboa R, Gomez-Rueda H, Martinez-Ledesma E, Martinez-Torteya A, Chacolla-Huaringa R, RodriguezBarrientos A, Tamez-Pena JG, Trevino V. SurvExpress: an online biomarker validation tool and database for cancer 
gene expression data using survival analysis. PLoS One. 2013; 8:e74250.

28. Vejnar CE, Zdobnov EM. MiRmap: comprehensive prediction of microRNA target repression strength. Nucleic Acids Res. 2012; 40:11673-11683.

29. Siegel RL, Miller KD, Jemal A. Cancer statistics, 2016. CA Cancer J Clin. 2016; 66:7-30.

30. Stros M, Launholt D, Grasser KD. The HMG-box: a versatile protein domain occurring in a wide variety of DNA-binding proteins. Cell Mol Life Sci. 2007; 64:2590-2606.

31. Thomas JO. HMG1 and 2: architectural DNA-binding proteins. Biochem Soc Trans. 2001; 29:395-401.

32. Murugesapillai D, McCauley MJ, Maher LJ 3rd, Williams MC. Single-molecule studies of high-mobility group B architectural DNA bending proteins. Biophys Rev. 2017; 9:17-40.

33. Seksenyan A, Kadavallore A, Walts AE, de la Torre B, Berel D, Strom SP, Aliahmad P, Funari VA, Kaye J. TOX3 is expressed in mammary $\mathrm{ER}(+)$ epithelial cells and regulates ER target genes in luminal breast cancer. BMC Cancer. 2015; 15:22.

34. Tessema M, Yingling CM, Grimes MJ, Thomas CL, Liu Y, Leng S, Joste N, Belinsky SA. Differential epigenetic regulation of TOX subfamily high mobility group box genes in lung and breast cancers. PLoS One. 2012; 7:e34850.

35. Sood AK, Geradts J, Young J. Prostate-derived Ets factor, an oncogenic driver in breast cancer. Tumour Biol. 2017; 39:1010428317691688.

36. Rodabaugh KJ, Mhawech-Fauceglia P, Groth J, Lele S, Sood AK. Prostate-derived Ets factor is overexpressed in serous epithelial ovarian tumors. Int J Gynecol Pathol. 2007; 26:10-15.

37. Guo M, Tomoshige K, Meister M, Muley T, Fukazawa T, Tsuchiya T, Karns R, Warth A, Fink-Baldauf IM, Nagayasu T, Naomoto Y, Xu Y, Mall MA, et al. Gene signature driving invasive mucinous adenocarcinoma of the lung. EMBO Mol Med. 2017; 9:462-481.

38. Steffan JJ, Koul S, Meacham RB, Koul HK. The transcription factor SPDEF suppresses prostate tumor metastasis. J Biol Chem. 2016; 291:20826.

39. Zhang X, Zhang Y, Wang L. Identifying New Tumor Suppressor in Liver Cancer Using Unbiased High-Throughput Approaches. The FASEB Journal. 2015; 29:999.2.

40. Leclerc D, Pham DN, Levesque N, Truongcao M, Foulkes WD, Sapienza C, Rozen R. Oncogenic role of PDK4 in human colon cancer cells. Br J Cancer. 2017; 116:930-936.

41. Cashman JR, Zhang J. Human flavin-containing monooxygenases. Annu Rev Pharmacol Toxicol. 2006; 46:65-100.

42. Krueger SK, Williams DE. Mammalian flavincontaining monooxygenases: structure/function, genetic polymorphisms and role in drug metabolism. Pharmacol Ther. 2005; 106:357-387.

43. Furuhashi M, Hotamisligil GS. Fatty acid-binding proteins: role in metabolic diseases and potential as drug targets. Nat Rev Drug Discov. 2008; 7:489-503.
44. Hsu BG, Chen YC, Lee RP, Lee CC, Lee CJ, Wang JH. Fasting serum level of fatty-acid-binding protein 4 positively correlates with metabolic syndrome in patients with coronary artery disease. Circ J. 2010; 74:327-331.

45. Nieman KM, Kenny HA, Penicka CV, Ladanyi A, BuellGutbrod R, Zillhardt MR, Romero IL, Carey MS, Mills GB, Hotamisligil GS, Yamada SD, Peter ME, Gwin K, et al. Adipocytes promote ovarian cancer metastasis and provide energy for rapid tumor growth. Nat Med. 2011; 17:1498-1503.

46. Guaita-Esteruelas S, Bosquet A, Saavedra P, Guma J, Girona J, Lam EW, Amillano K, Borras J, Masana L. Exogenous FABP4 increases breast cancer cell proliferation and activates the expression of fatty acid transport proteins. Mol Carcinog. 2017; 56:208-217.

47. Tang Z, Shen Q, Xie H, Zhou X, Li J, Feng J, Liu H, Wang W, Zhang S, Ni S. Elevated expression of FABP3 and FABP4 cooperatively correlates with poor prognosis in non-small cell lung cancer (NSCLC). Oncotarget. 2016; 7:46253-46262. https://doi.org/10.18632/oncotarget.10086.

48. Larsen CJ. Contribution of the dual coding capacity of the p16INK4a/MTS1/CDKN2 locus to human malignancies. Prog Cell Cycle Res. 1997; 3:109-124.

49. Bhattacharyya S, Sekar V, Majumder B, Mehrotra DG, Banerjee S, Bhowmick AK, Alam N, Mandal GK, Biswas J, Majumder PK, Murmu N. CDKN2A-p53 mediated antitumor effect of Lupeol in head and neck cancer. Cell Oncol (Dordr). 2017; 40:145-155.

50. Zhao R, Choi BY, Lee MH, Bode AM, Dong Z. Implications of Genetic and Epigenetic Alterations of CDKN2A (p16(INK4a)) in Cancer. EBioMedicine. 2016; 8:30-39.

51. Arnold DR, Gaspar RC, da Rocha CV, Sangalli JR, de Bem THC, Correa CAP, Penteado JCT, Meirelles FV, Lopes FL. Nuclear transfer alters placental gene expression and associated histone modifications of the placental-specific imprinted gene pleckstrin homology-like domain, family A, member 2 (PHLDA2) in cattle. Reprod Fertil Dev. 2017; 29:458-467.

52. Dellambra E, Patrone M, Sparatore B, Negri A, Ceciliani F, Bondanza S, Molina F, Cancedda FD, De Luca M. Stratifin, a keratinocyte specific 14-3-3 protein, harbors a pleckstrin homology $(\mathrm{PH})$ domain and enhances protein kinase $\mathrm{C}$ activity. J Cell Sci. 1995; 108:3569-3579.

53. Shiba-Ishii A, Kano J, Morishita Y, Sato Y, Minami Y, Noguchi M. High expression of stratifin is a universal abnormality during the course of malignant progression of early-stage lung adenocarcinoma. Int J Cancer. 2011; 129:2445-2453.

54. Schilling $\mathrm{SH}$, Hjelmeland AB, Radiloff DR, Liu IM, Wakeman TP, Fielhauer JR, Foster EH, Lathia JD, Rich JN, Wang XF. NDRG4 is required for cell cycle progression and survival in glioblastoma cells. J Biol Chem. 2009; 284:25160-25169.

55. Chu D, Zhang Z, Zhou Y, Li Y, Zhu S, Zhang J, Zhao Q, Ji G, Wang W, Zheng J. NDRG4, a novel candidate tumor 
suppressor, is a predictor of overall survival of colorectal cancer patients. Oncotarget. 2015; 6:7584-7596. https://doi. org/10.18632/oncotarget.3170.

56. Alavi M, Mah V, Maresh EL, Bagryanova L, Horvath S, Chia D, Goodglick L, Liu AY. High expression of AGR2 in lung cancer is predictive of poor survival. BMC Cancer. 2015; 15:655.

57. Park K, Chung YJ, So H, Kim K, Park J, Oh M, Jo M, Choi K, Lee EJ, Choi YL, Song SY, Bae DS, Kim BG, et al. AGR2, a mucinous ovarian cancer marker, promotes cell proliferation and migration. Exp Mol Med. 2011; 43:91-100.

58. Zhang J, Jin Y, Xu S, Zheng J, Zhang QI, Wang Y, Chen J, Huang Y, He X, Zhao Z. AGR2 is associated with gastric cancer progression and poor survival. Oncol Lett. 2016; 11:2075-2083.

59. Chae YK, Woo J, Kim MJ, Kang SK, Kim MS, Lee J, Lee SK, Gong G, Kim YH, Soria JC, Jang SJ, Sidransky D, Moon C. Expression of aquaporin 5 (AQP5) promotes tumor invasion in human non small cell lung cancer. PLoS One. 2008; 3:e2162.

60. Li J, Wang Z, Chong T, Chen H, Li H, Li G, Zhai X, Li Y. Over-expression of a poor prognostic marker in prostate cancer: AQP5 promotes cells growth and local invasion. World J Surg Oncol. 2014; 12:284.

61. Shan T, Cui X, Li W, Lin W, Li Y. AQP5: a novel biomarker that predicts poor clinical outcome in colorectal cancer. Oncol Rep. 2014; 32:1564-1570.

62. Rangel LB, Agarwal R, D'Souza T, Pizer ES, Alo PL, Lancaster WD, Gregoire L, Schwartz DR, Cho KR, Morin PJ. Tight junction proteins claudin-3 and claudin-4 are frequently overexpressed in ovarian cancer but not in ovarian cystadenomas. Clin Cancer Res. 2003; 9:2567-2575.

63. de Souza WF, Fortunato-Miranda N, Robbs BK, de Araujo WM, de-Freitas-Junior JC, Bastos LG, Viola JP, MorgadoDiaz JA. Claudin-3 overexpression increases the malignant potential of colorectal cancer cells: roles of ERK1/2 and PI3K-Akt as modulators of EGFR signaling. PLoS One. 2013; 8:e74994.

64. Takala H, Saarnio J, Wiik H, Soini Y. Claudins 1, 3, 4, 5 and 7 in esophageal cancer: loss of claudin 3 and 4 expression is associated with metastatic behavior. APMIS. 2007; 115:838-847.

65. Moldvay J, Jackel M, Paska C, Soltesz I, Schaff Z, Kiss A. Distinct claudin expression profile in histologic subtypes of lung cancer. Lung Cancer. 2007; 57:159-167.

66. Lu B, Yang M, Wang Q. Interleukin-33 in tumorigenesis, tumor immune evasion, and cancer immunotherapy. J Mol Med (Berl). 2016; 94:535-543.

67. Hu H, Sun J, Wang C, Bu X, Liu X, Mao Y, Wang H. IL-33 facilitates endocrine resistance of breast cancer by inducing cancer stem cell properties. Biochem Biophys Res Commun. 2017; 485:643-650.

68. He Z, Chen L, Souto FO, Canasto-Chibuque C, Bongers G, Deshpande M, Harpaz N, Ko HM, Kelley K, Furtado
GC, Lira SA. Epithelial-derived IL-33 promotes intestinal tumorigenesis in Apc Min/+ mice. Sci Rep. 2017; 7:5520.

69. Liu P, Jiao B, Zhang R, Zhao H, Zhang C, Wu M, Li D, Zhao X, Qiu Q, Li J, Ren R. Palmitoylacyltransferase Zdhhc9 inactivation mitigates leukemogenic potential of oncogenic Nras. Leukemia. 2016; 30:1225-1228.

70. Arnett HA, Viney JL. Immune modulation by butyrophilins. Nat Rev Immunol. 2014; 14:559-569.

71. Takauji Y, Kudo I, En A, Matsuo R, Hossain M, Nakabayashi K, Miki K, Fujii M, Ayusawa D. GNG11 (G-protein gamma subunit 11) suppresses cell growth with induction of reactive oxygen species and abnormal nuclear morphology in human SUSM-1 cells. Biochem Cell Biol. 2017; 95:517-523.

72. Hossain MN, Sakemura R, Fujii M, Ayusawa D. G-protein gamma subunit GNG11 strongly regulates cellular senescence. Biochem Biophys Res Commun. 2006; 351:645-650.

73. Zhu J, Chehab FF. Cutaneous Lipid Abnormalities In C7orf58 Knockout Mice Reveal A Critical Role For C7orf58 In Epidermal Lipid Homeostasis And The Late Steps Of Cholesterol Biosynthesis. Lipids: Regulation \& Mechanism of Disease: Endocrine Society). 2013. pp. OR05-3-OR-3.

74. Zhang L, Quan H, Wang S, Li X, Che X. MiR-183 promotes growth of non-small cell lung cancer cells through FoxO1 inhibition. Tumour Biol. 2015; 36:8121-8126.

75. Xu S, Huang H, Chen YN, Deng YT, Zhang B, Xiong XD, Yuan Y, Zhu Y, Huang H, Xie L, Liu X. DNA damage responsive miR-33b-3p promoted lung cancer cells survival and cisplatin resistance by targeting p 1 WAF1/CIP1. Cell Cycle. 2016; 15:2920-2930.

76. Zhu W, He J, Chen D, Zhang B, Xu L, Ma H, Liu X, Zhang Y, Le H. Expression of miR-29c, miR-93, and miR-429 as potential biomarkers for detection of early stage non-small lung cancer. PLoS One. 2014; 9:e87780.

77. Zhu W, Zhou K, Zha Y, Chen D, He J, Ma H, Liu X, Le H, Zhang Y. Diagnostic Value of Serum miR-182, miR183, miR-210, and miR-126 Levels in Patients with EarlyStage Non-Small Cell Lung Cancer. PLoS One. 2016; 11:e0153046.

78. Tian J, Hu L, Li X, Geng J, Dai M, Bai X. MicroRNA$130 \mathrm{~b}$ promotes lung cancer progression via PPARgamma/ VEGF-A/BCL-2-mediated suppression of apoptosis. J Exp Clin Cancer Res. 2016; 35:105.

79. Hou J, Aerts J, den Hamer B, van Ijcken W, den Bakker M, Riegman P, van der Leest C, van der Spek P, Foekens JA, Hoogsteden HC, Grosveld F, Philipsen S. Gene expressionbased classification of non-small cell lung carcinomas and survival prediction. PLoS One. 2010; 5:e10312.

80. Landi MT, Dracheva T, Rotunno M, Figueroa JD, Liu H, Dasgupta A, Mann FE, Fukuoka J, Hames M, Bergen AW, Murphy SE, Yang P, Pesatori AC, et al. Gene expression signature of cigarette smoking and its role in lung adenocarcinoma development and survival. PLoS One. 2008; 3:e1651. 
81. Selamat SA, Chung BS, Girard L, Zhang W, Zhang Y, Campan M, Siegmund KD, Koss MN, Hagen JA, Lam WL, Lam S, Gazdar AF, Laird-Offringa IA. Genome-scale analysis of DNA methylation in lung adenocarcinoma and integration with mRNA expression. Genome Res. 2012; 22:1197-1211.

82. Okayama H, Kohno T, Ishii Y, Shimada Y, Shiraishi K, Iwakawa R, Furuta K, Tsuta K, Shibata T, Yamamoto S, Watanabe S, Sakamoto H, Kumamoto K, et al. Identification of genes upregulated in ALK-positive and EGFR/KRAS/ ALK-negative lung adenocarcinomas. Cancer Res. 2012; 72:100-111.

83. Su LJ, Chang CW, Wu YC, Chen KC, Lin CJ, Liang SC, Lin $\mathrm{CH}$, Whang-Peng J, Hsu SL, Chen $\mathrm{CH}$, Huang CY. Selection of DDX5 as a novel internal control for Q-RTPCR from microarray data using a block bootstrap resampling scheme. BMC Genomics. 2007; 8:140.

84. Wei DC, Yeh YC, Hung JJ, Chou TY, Wu YC, Lu PJ, Cheng HC, Hsu YL, Kuo YL, Chen KY, Lai JM. Overexpression of T-LAK cell-originated protein kinase predicts poor prognosis in patients with stage I lung adenocarcinoma. Cancer Sci. 2012; 103:731-738.

85. Stearman RS, Dwyer-Nield L, Zerbe L, Blaine SA, Chan Z, Bunn PA Jr, Johnson GL, Hirsch FR, Merrick DT, Franklin WA, Baron AE, Keith RL, Nemenoff RA, et al. Analysis of orthologous gene expression between human pulmonary adenocarcinoma and a carcinogen-induced murine model. Am J Pathol. 2005; 167:1763-1775.
86. Bhattacharjee A, Richards WG, Staunton J, Li C, Monti S, Vasa P, Ladd C, Beheshti J, Bueno R, Gillette M, Loda M, Weber G, Mark EJ, et al. Classification of human lung carcinomas by mRNA expression profiling reveals distinct adenocarcinoma subclasses. Proc Natl Acad Sci U S A. 2001; 98:13790-13795.

87. Beer DG, Kardia SL, Huang CC, Giordano TJ, Levin AM, Misek DE, Lin L, Chen G, Gharib TG, Thomas DG, Lizyness ML, Kuick R, Hayasaka S, et al. Geneexpression profiles predict survival of patients with lung adenocarcinoma. Nat Med. 2002; 8:816-824.

88. Garber ME, Troyanskaya OG, Schluens K, Petersen S, Thaesler Z, Pacyna-Gengelbach M, van de Rijn M, Rosen GD, Perou CM, Whyte RI, Altman RB, Brown PO, Botstein $\mathrm{D}$, et al. Diversity of gene expression in adenocarcinoma of the lung. Proc Natl Acad Sci U S A. 2001; 98:13784-13789.

89. Wachi S, Yoneda K, Wu R. Interactome-transcriptome analysis reveals the high centrality of genes differentially expressed in lung cancer tissues. Bioinformatics. 2005; 21:4205-4208.

90. Collett D. (2015). Modelling survival data in medical research: CRC press.

91. Abel U, Berger J, Wiebelt H. CRITLEVEL: an exploratory procedure for the evaluation of quantitative prognostic factors. Methods Inf Med. 1984; 23:154-156.

92. Boulesteix AL. Maximally selected chi-square statistics for ordinal variables. Biom J. 2006; 48:451-462. 